\title{
North and South: A Regional Model of the UK
}

\author{
Patrick Minford $^{1,2} \cdot$ Yue Gai $^{3}$ D $\cdot$ David Meenagh $^{1}$
}

Accepted: 1 September 2021 /Published online: 28 October 2021

(c) The Author(s) 2021

\begin{abstract}
We set up a two-region model to study the policy challenge of bringing the North's income up to the level of the South in the UK. The model focuses on labour costs as the driver of output gains through the international competitiveness channel; and on tax/regulative costs to entrepreneurs as the driver of productivity growth. The empirical results show that the regional model behaviour fits the regional UK data behaviour over the period of 1986Q1 and 2019Q4, using the demanding Indirect Inference method. We also carry out a Monte Carlo power test, which shows the empirical results we obtain are trustworthy and can provide us a reliable guide for policy reform. The results suggest that in response to tax cuts and labour market reforms GDP in the North increases almost twice as much as GDP in the South. Given that a broad programme of tax cuts and regulatory reform would more than pay for itself in the long run, it must be considered as a highly attractive political agenda.
\end{abstract}

Keywords Regional study · DSGE model · Policy implication · Indirect Inference

JEL Classification E32 $\cdot \mathrm{E} 60 \cdot \mathrm{R} 10$

\section{Introduction}

In this paper we set out a model of the regional economy and apply it to UK data. Theories of regional behaviour, and in particular of relative income levels and growth are wide and diverse - for example, Borts and Stein (1964), Coyle and Sensier (2019), Krugman and Venables (1995), Henley (2005), Menon (2012), Venables (2020). These studies and numerous others pursue a variety of methods in

Yue Gai

yue.gai@swansea.ac.uk

1 Cardiff University, Cardiff, UK

2 CEPR, London, UK

3 Swansea University, Room 208, School of Management, Bay Campus, Swansea, UK 
confronting theories and facts. Our contribution here is to set out and test by a rigorous and powerful indirect inference procedure a theory of regional output, employment and growth based on open economy macroeconomics, in which we treat a region in the same way as we would a country economy, consisting of a population based there because of family and community ties. In this economy households supply labour to firms who produce heterogeneous country products that compete with rivals in world markets; migration to and from households abroad occurs and is part of the labour supply response to relative wages. Employment and output are then determined by open economy current account equilibrium. To this static equilibrium model we add an endogenous growth process in which households divert labour from work to entrepreneurial innovation in the firms they own; their incentive to innovate in this way depends on the tax and regulative costs imposed by the government in their region.

Our theory belongs to the real business and general equilibrium approach to regional economics, hence to the Real Business Cycle branch of macroeconomics (originated by Kydland and Prescott (1982)), its main difference being its disaggregation into two regions, North and South, linked by a common goods market but whose residents must produce locally and buy/produce housing within their own region. While much regional modelling treats the large rest of the economy as exogenous, here the regions interact and each respond to the national outcome; in this respect the model has much in common with two-country open-economy models for example, Chari et al. (2002), Kollmann et al. (2016) and Le et al. (2010).

It might be asked why we do not also apply the general equilibrium trade theory of comparative advantage and resource endowments to regional behaviour. The answer is that we want to focus on the regional macroeconomic policy context, which assumes importance in setting the extent of distortions in the markets for labour and innovation. These determine regional performance in total employment, output and productivity growth, which in turn, given resource endowments and comparative advantage determine the sectoral composition of output, with which we are not concerned here.

In what follows we begin with a discussion of the UK policy context and the surrounding debates. In the next section we outline the basic workings of the model, and summarise our main findings about the effects of different policy packages. We then go through the model in detail: in succeeding sections on its specification, the data used and our estimates of its parameters. We then review its behaviour in response to shocks, and in particular to policy changes. We conclude with a review of our policy recommendations.

\subsection{The UK Regional Policy Context and Debate}

A major policy challenge for the UK is to bring the North's income up to the level of that of the prosperous Southern regions of London, the South East and the South West which we call the South; in the 'North' we place all other regions, as is the usual practice. Our work has been stimulated by this policy challenge; much of the 
debate has not taken account of the manifold interactions within the economy, and our work is an attempt to provide a model in which these are fully integrated.

In the past few years a vigorous policy debate has begun over the issue of the North-South imbalance. A central element has been infrastructure. Many people have argued that infrastructure in the North has lagged behind that in the South, especially in transport. This mirrors the usual assumption when the problems of the North are mentioned relative to the South that 'more should be spent' on Northern infrastructure. This however misses the key point. This is that the North needs to achieve stronger cost competitiveness. The South achieves its results because it is highly competitive in world markets. This is certainly partly due to good infrastructure. But mainly it is the result of creating products and services that are in high demand internationally. In the 'Liverpool Model' of the UK as a whole (Marwaha et al. (1984)), transposed here to a region, the level of GDP is governed by UK cost competitiveness. This in turn is the result of the level of tax and regulatory costs on business.

In a parallel piece of work analysing how UK growth occurred during the Thatcher years, Minford and Meenagh (2019) showed that it was related to the cutting back of tax rates and regulation during the 1980s. This led to a surge in entrepreneurship which boosted productivity growth. We embed this same entrepreneurship model in the Regional Model here.

Essentially the same ideas apply to the North, as apply to the UK as a whole. The North, after all, is simply one part of the same UK organism.

It is helpful to start by understanding how London itself became such a competitive economy. Plainly much money has been spent on its transport infrastructure. But much of this has been in response to the economic activity it has created. i.e. to its success from other causes. Essentially this success has been tied up with the development of the City of London, the world's top financial centre. This in turn was supported by the provision and development of huge amounts of land in the docklands, feeding a demand for the City's services across the world. This City industry in turn was fed by supplies of skilled labour plentiful in the UK, due to expanding higher education and a liberal approach to skilled immigration. Other supply-side factors were the common law courts which made the UK an attractive place for dispute resolution, and the ample supply of land just noted, that gave the City space to expand.

Trade models give us corroborating sectoral insights. After abandoning EU protection of food and manufacturing, it will be the City and other service industries that expand as costs, especially of land, inflated by protection, come down (Minford and $\mathrm{Xu}$ (2018)).

Looking towards the North, what are the policy implications? Northern cities now have increased powers vested in mayors, just as London has had. This gives them an opportunity to think and act strategically to reduce costs and increase their regional competitiveness. If these cities and their cooperating surrounding regions can identify the infrastructure they need to support these moves, they now have a government strongly willing to oblige by providing it through central government funding. However, to be fair to central government this is not entirely new. Money has flowed from the centre to well-organised northern initiatives for some time. One 
only has to look at roads around Manchester or expenditures on the old docklands of central Liverpool to be aware that central government has spent liberally on northern development where needs have been identified. Essentially the system for providing infrastructure is demand-led by local needs, these in turn being created by economic growth.

The failures of the North to grow as fast as London cannot therefore be laid solely at the feet of central government unwillingness to spend on northern infrastructure. It looks rather as if it is the failure of the North to grow that has slowed down the associated infrastructure provision.

It might then well be asked: how can central government policy break into this slow-growth Northern equilibrium?

The answer is to be found, we suggest in this model, in the way the Thatcher government broke into the low-growth UK equilibrium - by lowering taxes and similar regulative restraints on cost competitiveness. Lower taxes work across the whole economy. By lowering general taxes and easing economy-wide regulations, economic activity is boosted across the whole economy. But such moves today, with a congested Southern economy, will primarily benefit the North, because that is where there is spare labour capacity. One can think of the process as a twostage one. Cutting taxes and regulative costs will boost competitiveness across the UK; but because of Southern congestion, Southern wages and so costs will rise in response, while Northern costs will rise much less. Hence the net effect will be to lower Northern costs and raise Northern competitiveness more than Southern.

It follows that in general the way to boost the North is to cut taxes and regulative costs across the UK as a whole, and then respond in the usual way to the resulting infrastructure demands from the North. It is not artificially to boost spending on Northern infrastructure independently of demand-led needs. The exception would be if some particular infrastructure project would itself stimulate some identifiable development — as could be argued is the case with the High Speed train programme; however, this has to be carefully evaluated. Too often infrastructure created to 'spur development' creates roads or bridges that 'lead to nowhere', i.e. to areas with little going on. In principle, infrastructure spending lowers costs for business by raising productivity. For examples one only has to think back to the way railways promoted development in the USA. But of course the railway era in which this promotion occurred also came to an end once railways went to most places. In the North today transport infrastructure already covers the area. To contribute, new transport links must improve on existing ones by lowering costs.

\subsection{The Model Workings and Key Model Policy Results}

We have embodied these ideas in this Regional UK model, which is derived from the same supply-side approach as originally taken in the Liverpool Model, used to advise Mrs.Thatcher's governments, with the addition of the entrepreneurship model of growth discussed above. In this model, each region, North and South, has a labour market which determines employment in general goods/services production. Households determine consumption and employment in a familiar way, responding 
to income and real wages after tax. Labour supply depends on net of tax wages, adjusted for prices. In the productive firms sector the cost competitiveness of general industries determines their sales success at home relative to imports and in foreign markets; apart from productivity, whose growth is affected by taxes and regulations on entrepreneurial households, cost competitiveness depends on wages. A general tax cut - e.g. of VAT or income tax — encourages labour supply and so lowers wages, raising cost competitiveness; net exports rise and the economy expands. The percent effect on GDP expansion is higher in the North than in the South because in the North labour is more plentiful, and therefore supply rises more as net of tax wages rise. This greater plentifulness of Northern labour is embodied in the model via a lower response of wage demands to rising employment (equivalent to a 'more elastic labour supply curve', a flatter SS curve in the labour quadrant in the following diagram). The mechanism can be seen in the 4-quadrant diagram that follows (See Fig. 1).

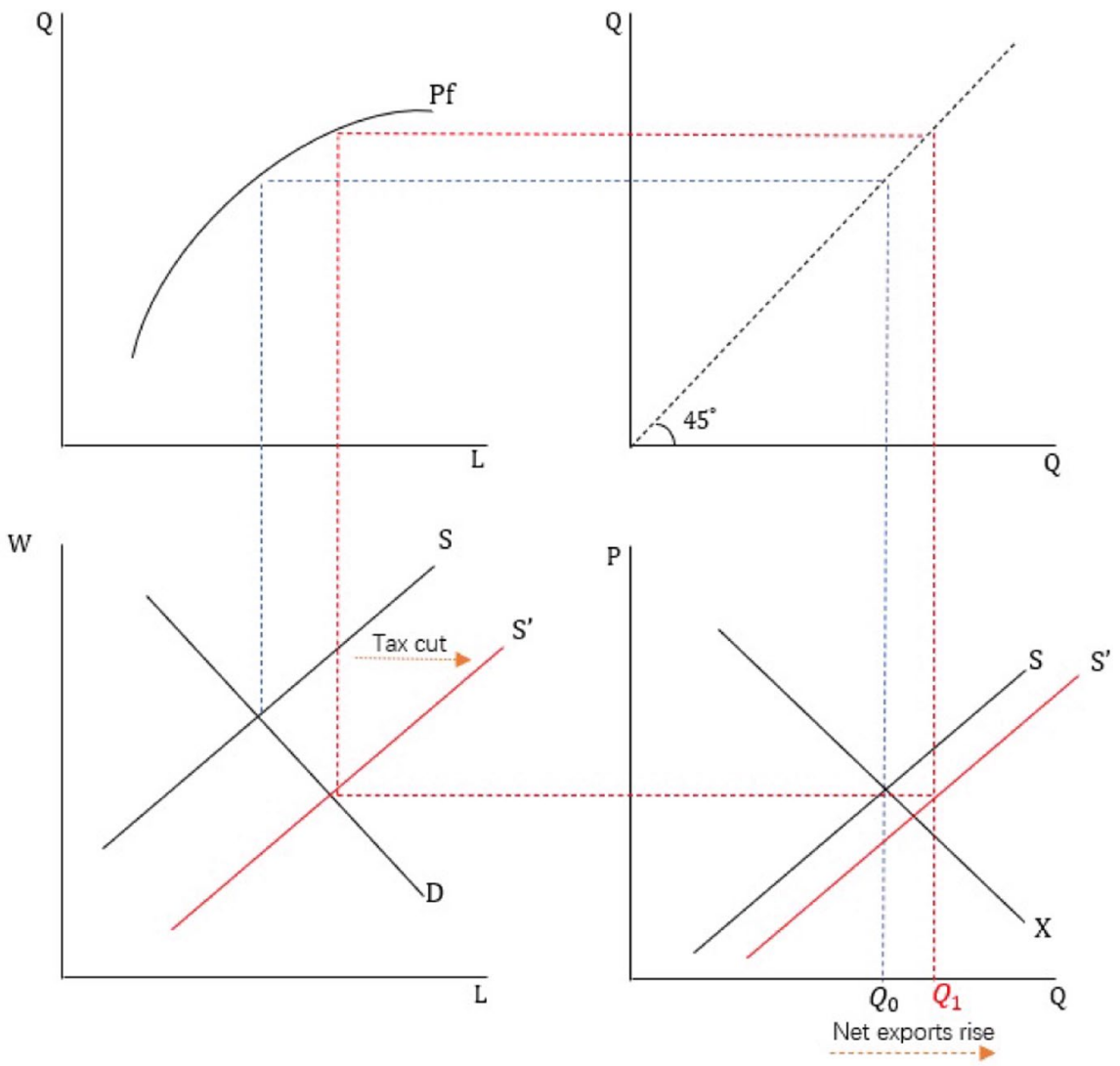

Fig. 1 The transmission mechanism of a tax cut 
Table 1 Long run Effects of different tax/regulative measures on North and South (Each package costed at $£ 10$ billion p.a.)

\begin{tabular}{llc}
\hline Percentage change in & $G D P_{N}$ & $G D P_{S}$ \\
\hline $\begin{array}{l}\text { Cut standard rate of income tax or VAT or other general income/consumption } \\
\text { tax }\end{array}$ & 1.1 & 0.5 \\
Cut Corporation tax rate & 0.8 & 0.4 \\
Cut marginal tax rate and regulative burden on Entrepreneurs/SMEs & 20 & 17 \\
Increase infrastructure spending in North & 1.6 & - \\
\hline
\end{tabular}

In each region the labour market clears via regional wages; labour is assumed to be immobile between regions, like land. House prices clear the regional market in housing; they are a component in regional consumer prices. Regional firms produce general goods and houses. They sell the housing regionally and the goods nationally. They can borrow at common national interest rates. At the national level exports are determined by foreign demand and UK competitiveness (relative home/ foreign prices adjusted for the exchange rate); imports by home demand and competitiveness. Then market-clearing in general goods determines real interest rates. Real interest rates in turn determine the real exchange rate through the Uncovered Interest Parity relationship according to which home real interest returns adjusted for expected real exchange rate movements and a risk-premium related to net foreign borrowing must equate with foreign real returns. In the long term the real exchange rate generates current account equilibrium to stop the risk-premium moving with new foreign borrowing.

We have fitted this model to UK data, finding the coefficients that get closest to matching, and are not rejected by, the UK facts - this being the indirect inference estimation procedure we describe in Sect. 4. From a policy viewpoint what interests us is the GDP effect of different tax cuts costing the Treasury the same, set for illustration at $£ 10$ billion each in the following Table 1, repeated here from the penultimate section below on Policy effects.

What is immediately striking is two things. First, all these measures bring worthwhile gains in GDP due to their supply-side effects. Second, the biggest gains by far come from cutting the tax and regulative burdens on entrepreneurs. Because these work by improving incentives to innovate and so raise productivity, and because they cost the Treasury relatively little, their effectiveness per pound of taxpayer cost is very high. Furthermore, they have their largest effect on GDP in the North, while also strongly reinforcing growth in the South, where enterprise is heavily entrenched. These policies remain in absolute terms the best booster for the North, while spreading growth nationally as well.

The model here appears to differ from much existing work, referenced above, on regional sources of growth. Some emphasise the migration of skilled labour, attracted by agglomeration in the South; some look to key infrastructure provision; some stress regional differences in 'ideas production' for R\&D; there is much other literature pointing to differences in capital availability, motivations of multi-nationals who dominate production and development, and numerous other factors. However, we are 
not downplaying these mechanisms here. Rather, our model posits that the underlying mechanisms driving all these differences are twofold: 1) the cost-competitiveness of production in the two regions. 2) the responsiveness of entrepreneurial innovation to incentives in each region. In the model, parameters that are potentially differentiated by region govern each of these mechanisms. Thus, there is a differential response of wages to consumption, which regulates the response of competitiveness to national policies on tax and regulation. Also, there can also be a differential entrepreneurial response to innovation incentives. Both these parameters are estimated on the data by the method of indirect inference, which has particular power in the small sample we are dealing with here, as elaborated below. Each of these parameters can be thought of as capturing empirically but parsimoniously the mechanisms dwelt on in the regional literature. For example, greater competitiveness and entrepreneurial innovation will attract capital from multinational corporations and other sources, and with it skilled migration such as of managerial talent; while we assume immobility of labour, we mean by this the unskilled bulk of the population. Then we also assume that infrastructure and public service provision generally largely follows need, in line with the established national UK 'Barnett formula' for public service provision. If we could identify the direct effects of these, we would; but there is no regional data on them as yet; it is an ongoing project for the ONS. Within the model, their effects and those of other factors we cannot directly measure enter the model error terms. These include, for example, exogenous factors driving regional entrepreneurial productivity, which have tended to be more strongly positive in the South, and those driving regional manufacturing demand and competitiveness - such as the rise in Chinese competition steadily competing industrial wages (largely Northern) downwards. Fortunately, from a policy viewpoint, we do have measures of the key tax and regulative policies that could be deployed with regional effect; these are included explicitly in the model.

\section{The Model Specification}

In this model, there are households who live in a region where they also work, for firms. The firms in this region are owned by these households but they produce goods that are sold in the UK and world markets where they compete with goods from other countries; other firms, also owned by these households produce housing which is sold in the region to the households in it. Firms produce, using labour, with a productivity level that is determined by the rate of innovation due to households' entrepreneurial activity; we do not explicitly model investment, assuming for simplicity a labour-only production function.

\subsection{Households}

Assume the representative households from North and South $(i=N, S)$ choose consumption $\left(C_{i, t}\right)$, housing $\left(H_{i, t}\right)$ and leisure $\left(x_{i, t}\right)$ to maximise the lifetime utility $(U)$ with preferences discounted by $\beta$, 


$$
U=\max E_{0}\left[\sum_{t=0}^{\infty} \beta^{t} \varepsilon_{i, t}^{r} u\left(C_{i, t}, H_{i, t}, x_{i, t}\right)\right]
$$

where $u($.$) takes the following constant relative risk aversion (CRRA) additively$ separable form:

$$
\begin{aligned}
u\left(C_{i, t}, H_{i, t}, x_{i, t}\right)= & \frac{1}{1-\rho_{1 i}} C_{i, t}^{\left(1-\rho_{1 i}\right)}+\frac{1}{1-\rho_{h i}} \varepsilon_{i, t}^{h} H_{i, t}^{\left(1-\rho_{h i}\right)} \\
& +\frac{1}{1-\rho_{2 i}} \varepsilon_{i, t}^{l} x_{i, t}^{\left(1-\rho_{2 i}\right)}
\end{aligned}
$$

Households enjoy positive utility from consumption goods $C_{i, t}$, housing services $H_{i, t}$ and leisure $x_{i, t} . \rho_{1 i}\left(\rho_{h i}\right)$ is the Arrow-Prat coefficient of relative risk aversion for consumption (housing), the inverse of $\rho_{1 i}\left(\rho_{h i}\right)$ being the intertemporal substitution elasticity between consumption (housing) in two consecutive periods. $\rho_{2 i}$ is the inverse of Frisch labour supply elasticity. The utility is subject to a preference shock $\varepsilon_{i, t}^{r}$, housing demand shock $\varepsilon_{i, t}^{h}$ and a labour supply shock $\varepsilon_{i, t}^{l}$.

The households allocate a unit of time into three parts: leisure, labour supply $N_{i, t}$ to the firm for the real wage $w_{i, t}$ and time spend on innovation $z_{i, t}$ such as human capital accumulation. Therefore, the time constraint that is normailsed at one follows ${ }^{1}$ :

$$
N_{i, t}+x_{i, t}+z_{i, t}=1
$$

The households' budget constraint (in real terms) is given by:

$$
\begin{aligned}
C_{i, t} & +p_{h i, t}\left[H_{i, t}-\left(1-\delta_{h}\right) H_{i, t-1}\right]+b_{i, t+1} \\
& +Q_{t} b_{t+1}^{f}=\left[w_{i, t} / p_{i, t}\left(1+\delta_{i} u n r_{t}-T l_{t}\right)\right] N_{i, t}-\Lambda_{t}+b_{i, t}\left(1+r_{t-1}\right) \\
& +Q_{t} b_{t}^{f}\left(1+r_{t-1}^{f}+\rho_{t-1}\right)
\end{aligned}
$$

The households get paid by supplying labour as well as the interest rate gain $\left(b_{i, t} r_{t-1}, b_{t}^{f} r_{t-1}^{f}\right)$ from purchasing domestic bonds $b_{i, t+1}$ and foreign bonds $b_{t+1}^{f} . T l_{t}$ is tax on the supply side of labour through the whole country. $\Lambda_{t}$ is the lump-sum tax. $u n r_{t}$ is defined as unionisation rate (proxying union power). $\delta_{i}$ is the elasticity of wage related to the unionisation rate, which pushes wages up. $p_{i, t}$ is the regional CPI, which differs from the national CPI by the difference in the regional from the national house price, weighted by the housing share. $p_{h i, t}$ is the relative price of houses and $\delta_{h}$ is the depreciation rate of houses. $Q_{t}$ measure the unit cost of the real foreign bond. This is the price of the foreign consumption good relative to the consumer price level at home (the numeraire of the model and hence set at unity) defined as $Q_{t}=p_{t}^{f} \hat{E}_{t} . \hat{E}_{t}$ is the nominal exchange rate (the domestic currency value of one unit of foreign currency). The variable $Q_{t}$ therefore is the real exchange rate,

\footnotetext{
1 We think the choice of $z_{i, t}$ contributes to the productivity growth, which is left aside for now and will be discussed in the following section. In this section, we only focus households optimal choice between labour supply and leisure.
} 
which moves inversely to the terms of trade, the price of exports relative to the price of imports. $\rho_{t}$ is the risk-premium driven by the level of foreign $\operatorname{debt}^{2}$.

The optimisation problem of households is to maximise Eq. (2) by choosing $C_{i, t}, H_{i, t}, x_{i, t}, b_{i, t+1}$, and $b_{t+1}^{f}$ subject to Eq. (4). The optimal conditions imply the standard Euler equation (Eq. 5), housing demand (Eq. 6), the optimal substitution between consumption and leisure to the real wage (Eq. 7) and real uncovered interest parity (Eq. 8).

$$
\begin{gathered}
\varepsilon_{i, t}^{r} C_{i, t}^{-\rho_{1} i}=\beta\left(1+r_{t}\right) E_{t}\left[\varepsilon_{i, t+1}^{r} C_{i, t+1}^{-\rho_{1 i}}\right] \\
\varepsilon_{i, t}^{h} H_{i, t}^{-\rho_{h i}}=p_{h i, t} \varepsilon_{i, t}^{r} C_{i, t}^{-\rho_{1} i}-\beta E_{t}\left[p_{h i, t+1}\left(1-\delta_{h}\right) \varepsilon_{i, t+1}^{r} C_{i, t+1}^{-\rho_{1 i}}\right] \\
\frac{\varepsilon_{i, t}^{l} x_{i, t}^{-\rho_{2 i}}}{C_{i, t}^{-\rho_{1 i}}}=w_{i, t} / p_{i, t}\left(1+\delta_{i} u n r_{t}-T l_{t}\right) \\
\left(1+r_{t}\right)=E_{t} \frac{Q_{t+1}}{Q_{t}}\left(1+r_{t}^{f}+\rho_{t}\right)
\end{gathered}
$$

The domestic country has a perfectly competitive final goods sector, which produce a version of the final good that is distinct from the product of the foreign country. The model features a multi-level utility structure (Philip et al. (2014)). Households from North and South in the home country consume both domestic good $C_{t}^{d}$ and imported good $C_{t}^{f}$ with home price $p_{t}$ and foreign price $Q_{t}$. The level of total consumption $C_{t}\left(C_{t}=C_{N, t}+C_{S, t}\right)$ chosen above must satisfy the expenditure constraint across domestic and imported goods,

$$
C_{t}=p_{t} C_{t}^{d}+Q_{t} C_{t}^{f}
$$

$C_{t}^{d}$ and $C_{t}^{f}$ are chosen to maximise $\tilde{C}_{t}$ through the following CES aggregator utility function (Eq. 10), subject to the constraint that $C_{t} \leq C_{t}$ :

$$
\max \tilde{C}_{t}=\left[\omega\left(C_{t}^{d}\right)^{-\rho}+(1-\omega) \zeta_{t}\left(C_{t}^{f}\right)^{-\rho}\right]^{-\frac{1}{\rho}}
$$

At the point of the maximum the constraint is binding, so that the consumptionequivalent utility, $C_{t}$, is equal to the amount spent on consumption goods, $C_{t}$ (the variable that appears in the budget constraint of the main consumer problem). We follow the assumption here: domestic consumers have some fixed preference bias towards the domestic good, reflected in the parameter $\omega ; 0<\omega<1$. The demand for imports is subject to a shock, $\zeta_{t}$. The elasticity of substitution between domestic and

\footnotetext{
$\overline{2} b_{t+1}^{f}$ costs what a unit of the foreign consumption basket $\left(C_{t}^{*}\right)$ would cost, i.e. $p_{t}^{*}$ (the foreign CPI). In domestic currency, this is $p_{t}^{*} \hat{E}_{t}$. Assuming $p_{t}^{*} \simeq p_{t}^{f}$ (i.e. exported goods from the home country have little impact on the larger foreign country) the unit cost of $b_{t+1}^{f}$ is $Q_{t}$.
} 
foreign varieties is constant at $\sigma=\frac{1}{1+\rho}$. The first order conditions give the following domestic demand for foreign produced goods (import):

$$
C_{t}^{f}=I M_{t}=(1-\omega) \zeta_{t}\left(Q_{t}\right)^{-\sigma} C_{t}
$$

From Eq. (11), the symmetric equation describing foreign demand for domestic goods (exports) relative to general foreign is:

$$
\left(C_{t}^{d}\right)^{\star}=E X_{t}=\left(1-\omega^{F}\right) \zeta_{t}^{\star}\left(Q_{t}^{\star}\right)^{-\sigma^{F}} C_{t}^{\star}
$$

* shows a foreign variable and $\omega^{F}$ and $\sigma^{F}$ are respectively the foreign equivalents to $\omega$ and $\sigma . Q_{t}^{\star}$ is the foreign equivalent of $Q_{t}$; we assume it is closely approximated by $Q^{-13} \cdot \zeta_{t}^{\star}$ is the random preference shock to the demand for exports. The foreign consumption is represented as $C_{t}^{\star}$. The loglinear approximation for Eq. (12) is derived by taking a first order Taylor expansion. This yields:

$$
\ln \left(C_{t}^{d}\right)^{\star}=\check{c}+\ln C_{t}^{\star}+\sigma^{F} \frac{1}{\omega} \ln Q_{t}+\varepsilon_{t}^{e x}
$$

where $\check{c}$ collects constants and $\varepsilon_{t}^{e x}=\sigma^{F}\left[\ln \zeta_{t}^{\star}+\frac{1-\omega}{\omega} \frac{1}{\rho} \ln \zeta_{t}\right]$

We assume there are no capital controls, the balance of payments is expressed in real terms as following:

$$
\Delta b_{t+1}^{f}=r_{t}^{f} b_{t}^{f}+p_{t} E X_{t}-Q_{t} I M_{t}
$$

Via the overall balance of payments constraint, the current account surplus (real net exports plus income flows on foreign assets) and the capital account deficit (the decrease in net foreign assets) sum to zero.

\subsection{Firms and Production Sectors}

Representative firms in North and South $(i=N$ and $S)$ produce both goods and houses $(j=c$ and $h$ ) following a Cobb-Douglas labour-only production function (Eq. 14). The non-stationary individual productivity of different sectors in the two regions $A_{j i, t}$ evolves as the process (Eq. 15), which depends on the households choosing time spent in some innovation-enhancing activity $z_{i, t}$ as well as the aggregate productivity shock $v_{j i, t}^{A}$.

$$
Y_{j i, t}=A_{j i, t} N_{j i, t}^{\alpha}
$$

\footnotetext{
${ }^{3} Q_{t}^{*}=\frac{P_{t}}{P_{t}^{*}}$ since $Q_{t}=\frac{P_{t}^{t}}{P_{c, t}}$ and $P_{c, t}$ is the numeraire, so $Q_{t}=P_{t}^{f}$. We assume $P_{t}^{*} \simeq P_{t}^{f}$ if the exported goods from the home country have little impact on the larger foreign country.
} 


$$
\frac{A_{j i, t+1}}{A_{j i, t}}=\theta_{1 j i}+\theta_{2 j i} z_{i, t}+v_{j i, t}^{A}
$$

We have no good data on regional infrastructure capital, $K_{i, t}$, which we assume affects productivity via $\theta_{3 i}$, the capital share, as 0.3 . For policy simulation, we treat $K_{i, t}$ as an exogenous variable in simulation only.

The goods and housing firms in different regions maximise their expected profits $\pi_{j i, t}$, subject to prices, wages and their labour-only production function,

for goods:

$$
\pi_{c i, t}=\left(1-T f_{t}\right) p_{t} Y_{c i, t}-w_{i, t}\left(\varepsilon_{i, t}^{n c} N_{c i, t}\right)
$$

and for housing:

$$
\pi_{h i, t}=\left(1-T f_{t}\right) p_{h i, t} Y_{h i, t}-w_{i, t}\left(\varepsilon_{i, t}^{n h} N_{h i, t}\right)
$$

General goods are sold nationally and internationally at the home price, $p_{t}$, while housing goods are sold at price $p_{h i, t}$. The government levies a general consumption tax at the rate $T f_{t}$. The tax rate is assume to be the same in the whole country. $\varepsilon_{i, t}^{n j}$ is the regional labour demand shock in different sectors. We assume the real wage rate $w_{i, t}$ is same in goods and housing sectors but different in North and South.

The optimal labour demand for goods is given by:

$$
N_{c i, t}=\alpha \frac{\left(1-T f_{t}\right) p_{t} Y_{c i, t}}{w_{i, t} \varepsilon_{i, t}^{n c}}
$$

The optimal labour demand for housing is given by:

$$
N_{h i, t}=\alpha \frac{\left(1-T f_{t}\right) p_{h i t} Y_{h i, t}}{w_{i, t} \varepsilon_{i, t}^{n h}}
$$

\subsection{Government}

Government spends $\left(G_{t}\right)$ subject to its budget constraint:

$$
G_{t}+b_{t}\left(1+r_{t-1}\right)=R_{t}+b_{t+1}
$$

Government issues bonds and sets the lump-sum tax, $T_{t}$. The bonds issued in different regions are as same as the national bonds, so $b_{i, t}=b_{t}$. The tax revenues cover spending and the current interest bill: $R_{t}=G_{t}+r_{t-1} b_{t}$. so $b_{t}=b_{t+1}$.

Revenue $R_{t}$ consist of tax on innovation, general consumption tax, tax on labour and the lump-sum tax, which follows:

$$
R_{t}=\tau_{t} z_{i, t}+p_{(h i), t} Y_{j i, t} T f_{t}+w_{i, t} N_{i, t} T l_{t}+\Lambda_{t}
$$

$\tau_{t}$ is the cost of time spent in innovation $z_{i, t}$. Government spending $G_{t}$ is treated as an exogenous variable, which follows an $\operatorname{AR}(1)$ process. 


\subsection{Endogenous Growth of Productivity}

In the Production sectors, according to Eq. (15), we know that productivity growth depends on the innovation-enhancing activity $z_{i, t}$. Therefore, in this section, we focus on how the household's optimal choice of $z_{i, t}$ affects productivity growth. The idea is conceptually similar to Lucas and Robert (1990), where the households try to find out the balance between time spent in productivity-enhancing activity and labour supply. In the households section above, we discussed the optimal conditions for time allocations between labour supply $N_{i, t}$ and leisure $x_{i, t}$. In this section, the trade-off between $z_{i, t}$ and $N_{i, t}$ will be explored. Given the time endowment (Eq. 3), once we find out the previous two relationships, the third one (relationship between $z_{i, t}$ and $x_{i, t}$ ) follows.

If we go back to the households' problem, in this case we focus on the optimal choice of $z_{i, t}$. Here we follow Minford and Meenagh (2019), where households, as owners of firms, maximise their dividends from firms by spending time on entrepreneurial innovation that raises their productivity. The optimal choice of $z_{i, t}$ is given by:

$$
\frac{d L}{d z_{i, t}}=0=-\beta^{t} \lambda_{t} w_{i, t} / p_{i, t}\left(1+\delta_{i} u n r_{t}-T l_{t}\right)-\beta^{t} \lambda_{t} \tau_{t}+E_{t} \sum_{s=1}^{\infty} \beta^{t+s} \lambda_{t+s} \frac{d A_{j i, t+s}}{d z_{i, t}} N_{j i, t+s}
$$

Here the cost of spending time on innovation is the loss of current wages in normal work plus the cost of the tax, $\tau$, to be set against the discounted future gains of output from the higher productivity applied to the currently projected stream of labour inputs.

We substitute out the multiplier and rearrange Eq. (22) using the geometric sequence sum formula:

$$
\beta^{t} \varepsilon_{i, t}^{r} C_{i, t}^{-\rho_{1} i} w_{i, t} / p_{i, t}\left(1+\delta_{i} u n r_{t}-T l_{t}\right)+\beta^{t} \varepsilon_{i, t}^{r} C_{i, t}^{-\rho_{1} i} \tau_{t}=\theta_{2} \frac{A_{j i, t}}{A_{j i, t+1}} E_{t} \sum_{s=1}^{\infty} \beta^{t+s} \varepsilon_{i, t+s}^{r} C_{i, t+s}^{-\rho_{1} i} Y_{j i, t+s}
$$

Equation (23) shows the trade-off between $N_{i, t}$ and $z_{i, t}$. The first term represents the return on the marginal unit of $N_{i, t}$, and the following two terms show the subsidy incentives for the innovation-enhancing activity $z_{i, t}$ and the expected output increase as the result of increase in $z_{i, t}$. Equation (23) can be rewritten as follows:

$$
\frac{A_{j i, t+1}}{A_{j i, t}}=\theta_{2} \frac{E_{t} \sum_{s=1}^{\infty} \beta^{s} \varepsilon_{i, t+s}^{r} C_{i, t+s}^{-\rho_{1} i} Y_{j i, t+s}}{\varepsilon_{i, t}^{r} C_{i, t}^{-\rho_{1} i}\left(w_{i, t} / p_{i, t}\left(1+\delta_{i} u n r_{t}-T l_{t}\right)+\tau_{t}\right)}
$$

We assume the preference shock to consumption $\varepsilon_{i, t}^{r}$ follows the $\operatorname{AR}(1)$ process: $\varepsilon_{i, t}^{r}=\rho_{r i} \varepsilon_{i, t-1}^{r}+v_{r, t} . \rho_{1 i}$ is set to unity for simplicity and this value is also used in our empirical study. As households have the unit cost $\tau_{t}$ as well as the unit opportunity cost $w_{i, t}$, we define an "entrepreneurship penalty rate" $\tau_{t}^{\prime}=\tau_{t} / w_{i, t}$ to reflect the tax as a rate on wages. Equation (24) can be turned into Eq. (25) by approximating $Y_{j i, t} / C_{i, t}$ as a random walk: 


$$
\frac{A_{j i, t+1}}{A_{j i, t}}=\theta_{2} \frac{\beta \rho_{r i} \frac{Y_{j i, t}}{w_{i, t} / p_{i, t}\left(1+\delta_{i} u n r_{t}-T l_{t}\right)}}{\left(1-\beta \rho_{r i}\right)\left(1+\tau_{t}^{\prime}\right)}
$$

We can linearise Eq. (25) as Eq. (26) by relegating $Y_{j i, t} /\left(w_{i, t} / p_{i, t}\right)\left(1+\delta_{i} u n r_{t}-T l_{t}\right)$ into the error term:

$$
\ln A_{j i, t+1}-\ln A_{j i, t}=\phi_{1, j i}-\phi_{2, j i} \tau_{t}^{\prime}+\varepsilon_{j i, t}^{A}
$$

We specify $\tau_{t}^{\prime}$ as a function of the economy-wide money costs of entrepreneurship relative to the average wage $\left(\tau_{t}^{\prime}=\tau_{t} / w_{t}\right)$. We assume it is the same in North and South.

These incentives to innovation also affect the optimal labour supply and define $\frac{\partial z_{i, t}}{\partial \tau_{t}^{\prime}} \equiv c_{1 i}{ }^{4}$. We include this in labour supply (Eq. 7). The total derivative of the time endowment (Eq. 3) implies $d x_{i, t}=-d N_{i, t}-d z_{i, t}$, so $\frac{d x_{i, t}}{x_{i, t}}=\frac{-d N_{i, t}-d z_{i, t}}{x_{i, t}}$. We assume that in the absence of innovation activity - the base line - households spend half their time on $N_{i, t}$ and half on $x_{i, t .}$ so $N=x=\frac{1}{2}$ in the baseline.

$$
\frac{d x_{i, t}}{x}=d \ln x_{i, t} \approx-d \ln N_{i, t}-\frac{d z_{i, t}}{N}=-d \ln N_{i, t}-2 d z_{i, t}
$$

Substitute into the loglinearised labour supply equation using Eq. (27) and also include the effect of unemployment benefit on labour supply, we obtain:

$$
\ln w_{i, t}=\gamma\left(\ln p_{h i t}-\ln p_{h t}\right)+\rho_{2 i} \ln N_{i, t}+\rho_{1 i} \ln C_{i, t}+\rho_{2 i} 2 c_{1 i} \tau_{t}^{\prime}+T l_{t}+U B_{t}+\delta_{i} u n r_{t}+\varepsilon_{i, t}^{l}
$$

\subsection{The National Economy}

We aggregate all the regional variables at the national level. From the following equations, we can see that the total general goods $\left(Y_{c, t}\right)$ is the sum of general goods in North and South. GDP in North $\left(G D P_{N, t}\right)$ is defined as the sum of output in both goods and housing sector, same in $G D P_{S, t}$. The total GDP $\left(G D P_{t}\right)$ is the sum of GDP in North and South. Total consumption $\left(C_{t}\right)$ is defined as the aggregation of regional consumption. The total labour demand in North (South) is defined as $N_{N, t}\left(N_{S, t}\right)$ The national housing price $\left(p_{h, t}\right)$ is defined as the average regional housing price.

$$
\begin{gathered}
Y_{c, t}=Y_{c N, t}+Y_{c S, t} \\
G D P_{N, t}=Y_{c N, t}+p_{h N, t} Y_{h N, t}
\end{gathered}
$$

\footnotetext{
${ }^{4}$ Rearrange for $z_{i, t}$ by Substituting into Eq. (10) from Eq. (5). then take first order derivative with respect to $\tau_{t}^{\prime}$ and get $c_{1 i}=\frac{\beta \rho_{r i} \frac{Y}{w / p\left(1+\delta_{i} u r r-T\right)}}{\left(1-\beta \rho_{r i}\right)\left(1+\tau^{\prime}\right)^{2}}$.
} 


$$
\begin{gathered}
G D P_{S, t}=Y_{c S, t}+p_{h S, t} Y_{h S, t} \\
G D P_{t}=G D P_{N, t}+G D P_{S, t} \\
C_{t}=C_{N, t}+C_{S, t} \\
N_{N, t}=N_{c N, t}+N_{h N, t} \\
N_{S, t}=N_{c S, t}+N_{h S, t} \\
p_{h, t}=\left(p_{h N, t}+p_{h S, t}\right) / 2
\end{gathered}
$$

\subsection{Market Clearing}

The goods market clears when:

$$
Y_{c, t}=C_{t}+E X_{t}-I M_{t}+G_{t}
$$

where $\ln G_{t}=\rho_{G} \ln G_{t-1}+v_{t}^{G}$.

The housing market clears in each region via the price of housing so that:

$$
Y_{h i, t}=H_{i, t}-\left(1-\delta_{h}\right) H_{i, t-1}
$$

\subsection{Exogenous Variables}

We have explained how households and firms choose to behave; however their actions are impacted by shocks from the economic and policy environment, the exogenous (outside) variables they cannot control. All these shocks, whether regional or national, are stationary (that is, apart from any time trends driving them steadily up or down over time, they return eventually back to their starting point) except the regional productivity shocks in goods and housing sectors - the 'productivity processes' growth is impacted by stationary shocks, whose impact on the level of productivity is therefore permanent, so that these productivity processes are non-stationary - once disturbed by a growth shock they do not revert. Some of the stationary shocks are residuals in the structural equations such as the regional labour supply shock $\left(\varepsilon_{i, t}^{l}\right)$, regional preference shocks $\left(\varepsilon_{i, t}^{r}\right)$, national export shocks $\left(\varepsilon_{t}^{e x}\right)$, and national import shocks $\left(\varepsilon_{t}^{i m}\right)$. Some of the shocks are exogenous policy variables such as government spending $\left(G_{t}\right)$, regional infrastructure capital $\left(K_{i, t}\right)$, tax on innovation $\left(\tau_{t}^{\prime}\right)$, tax on firm $\left(T f_{t}\right)$ etc. All the stationary residuals take the following $\mathrm{AR}(1)$ form:

$$
\varepsilon_{(i), t}^{k}=a_{k(i)}+b_{k(i)} t+\rho_{k(i)} \varepsilon_{(i), t-1}^{k}+v_{(i), t}^{k}
$$


where $v_{(i), t}^{k}$ is an i.i.d mean zero innovation term, and $k$ represents different structural residuals and exogenous variables, $i$ shows North or South.

The non-stationary regional productivity shock in goods and housing sector $A_{j i, t}$ are driven by an $\mathrm{AR}(1)$ shock and by exogenous variable $\tau_{t}^{\prime}$, which are modelled as a unit root process based on Eq. (26):

$$
\begin{gathered}
A_{j i, t}-A_{j i, t-1}=\phi_{1, j i}+\phi_{2, j i} \tau_{t-1}^{\prime}+\varepsilon_{j i, t}^{A} \\
\varepsilon_{j i, t}^{A}=\rho_{j i}^{A} \varepsilon_{j i, t-1}^{A}+v_{j i, t}^{A}
\end{gathered}
$$

where $i$ shows North or South, $j$ represents goods or housing sector.

The complete log-linearised model is listed in Appendix 1.

\section{The Data}

According to the ONS, there are 12 regions in the UK. We define London, South East and South West as South, the rest is North. So, the North consists of North East, North West, Yorkshire, East Midlands, West Midlands, East of England, Wales, Scotland and Northern Ireland. Therefore, the data in North and South are the weighted average of different regions.

The sample is unfiltered UK macroeconomic data from 1986Q1 to 2019Q4. The time series in North and South we have collected and used are: regional output in goods sector, regional output in housing sector, regional labour demand in goods sector, regional labour demand in housing sector, regional labour supply, regional consumption, regional housing demand, regional housing price and regional wage. Figures 2 and 3 plot these time series in North and South. Figure 4 shows the
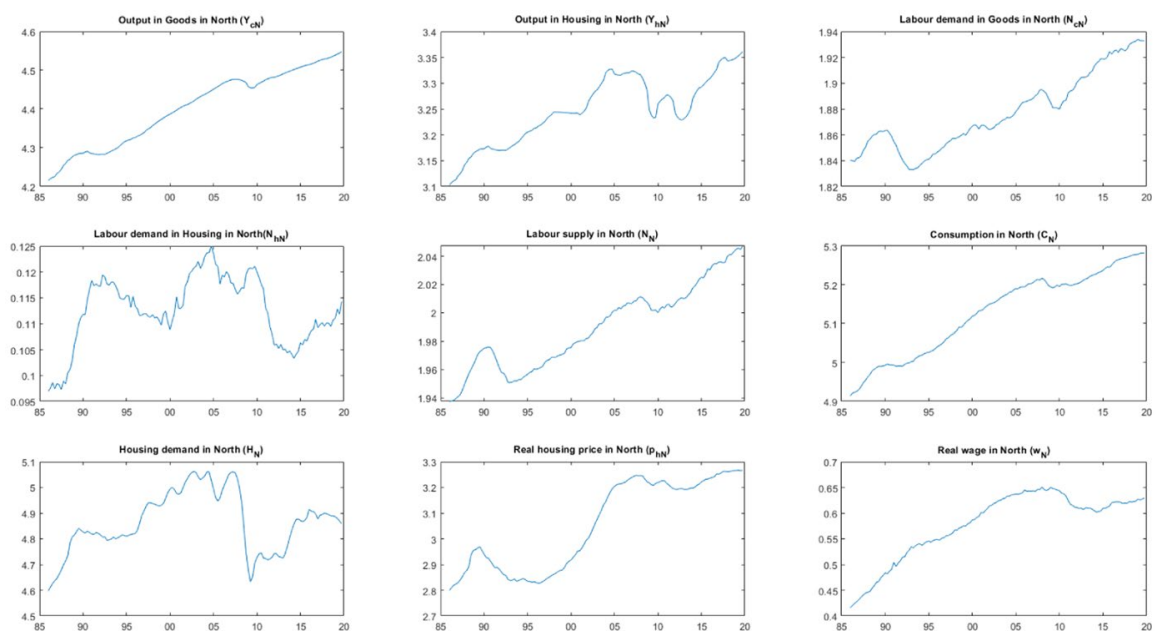

Fig. 2 North Data 

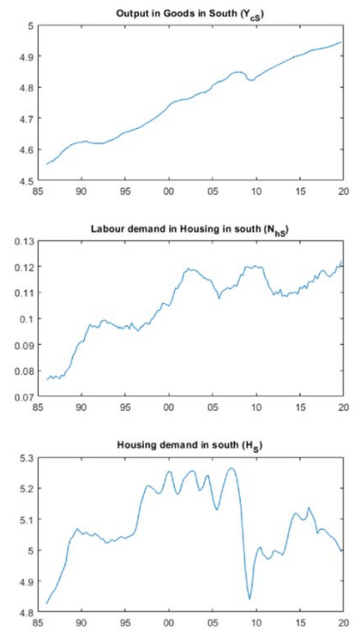
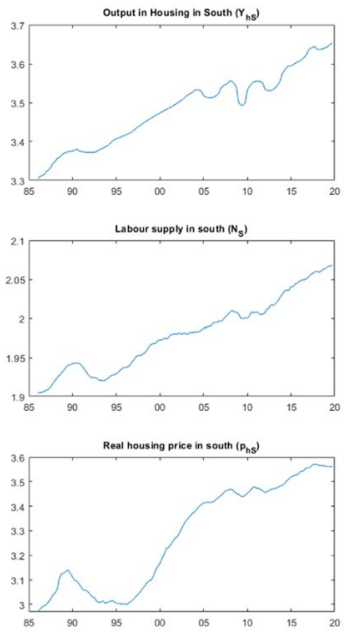
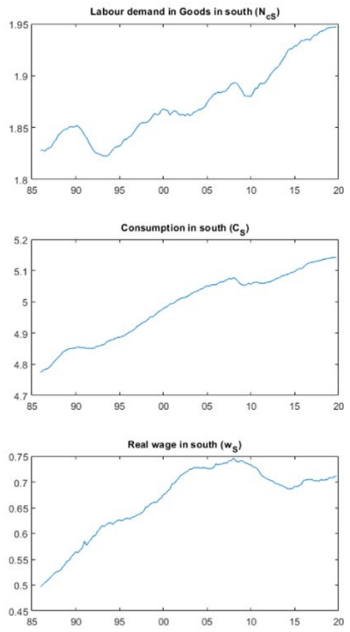

Fig. 3 South Data

national level data we used in the model. They are real GDP, real total consumption, real housing demand, total labour demand in housing and goods sector, price of goods, foreign price, net foreign assets, exchange rate, real interest rate, imports and exports. The different taxes and regulations shown are the tax on labour income, the tax on firms' income, the tax on innovation/entrepreneurship, the union membership rate (proxying union powers) and unemployment benefit.

For tax on labour, we consider the basic UK income tax rate, the National Insurance (NI) employee's rate, tax on general income and consumption. Another tax, tax on firms, is collected using NI contribution rate by employer. The variable, $\tau^{\prime}$,
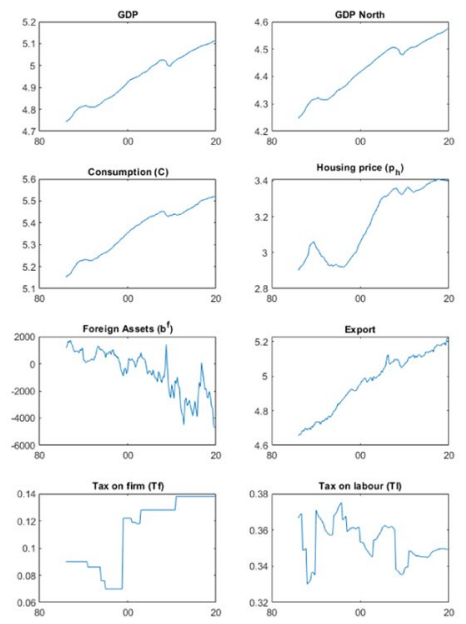
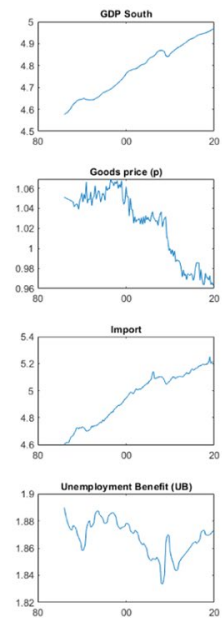
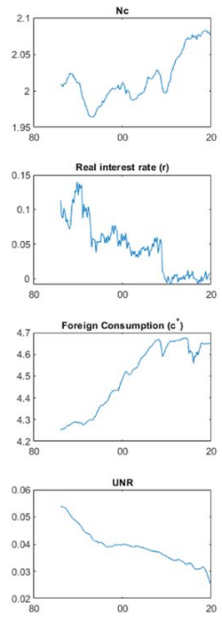
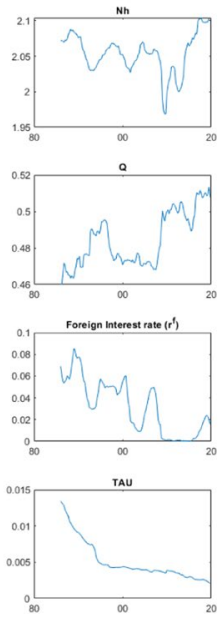

Fig. 4 National Data 
imposing costs on innovation, consists of two key components of the business environment: regulation and tax. On regulation, we focus on the labour market and use collective bargaining coverage from OECD. At the same time, we also consider the income tax and corporation tax in $\tau^{\prime}$. A detailed description of the data can be found in Appendix 2.

\section{Indirect Inference-Our Estimation and Testing Method}

In this section, we set out and explain our methodology of model testing and parameter estimation: Indirect Inference (II), developed by Le et al. (2011) building on Smith (1993). II is based on the idea that if the structural model is true in terms of both specification and parameters, the properties of the actual data should come from the distribution of the properties of the simulated data with some critical minimum probability. The main reason for using this method is its power in small samples, such as we have here. FIML is badly biased as an estimator in small samples and likelihood tests based on it have low power, whereas II is an unbiased estimator and tests based on it have substantial power — Le et al. (2016), Meenagh et al. (2019) survey its features.

The II method has been in familiar use for many years, in the form of the Simulated Method of Moments, SMM; recent developments have generalised it as Indirect Inference, allowing considerable flexibility in the choice of data features to be matched, known as the 'auxiliary model'. It has been used increasingly widely in applied work - Akcigit and Kerr (2018), Guvenen and Smith (2014), Minford and Peel (2019) surveys its spreading use in applied macro modelling. The approach involves hypothesising that the model being estimated is the true data generating mechanism, DGM; the data is then succinctly described by, for example, moments under SMM. If so then the moments found in the data should come from the model with a probability in excess of the threshold rejection level of $5 \%$, when the usual 95\% confidence level is used. To discover the probability distribution of the Moments according to the model, the model is simulated by bootstrapping the random shocks perturbing it many times; the resulting joint distribution of the moments is what the model implies if it is the true DGM. If the data-based moments have a probability less than 5\% according to this distribution, the model is rejected. Estimation by II involves searching over model parameters to find the set that is least rejected above the 5\% level - this set is the II estimator.

The data properties can be captured by a simple 'auxiliary model' such as a VAR, impulse response functions or the moments as in the SMM. It turns out (Meenagh et al. (2019)) that the results are similar in each case. Define the parameters of the structural model and the auxiliary model as $\theta$ and $\beta$ respectively. We first use the actual data to estimate the auxiliary parameters, say $\widehat{\beta}$. Given the null hypothesis $H_{0}: \theta=\theta_{0}$, we simulate $S$ samples using the structural model and estimate the auxiliary parameters using each simulated sample to obtain estimators $\widetilde{\beta}_{s}\left(\theta_{0}\right) ; s=1, \cdots, S$. To evaluate whether $\hat{\beta}$ comes from the distribution of $\left\{\widetilde{\beta}_{s}\left(\theta_{0}\right)\right\}$, we compute the Wald statistic 


$$
\text { Wald }_{a}=\left[\hat{\beta}-\overline{\widetilde{\beta}_{s}\left(\theta_{0}\right)}\right]^{\prime} W\left(\theta_{0}\right)^{-1}\left[\hat{\beta}-\overline{\widetilde{\beta}_{s}\left(\theta_{0}\right)}\right]
$$

which asymptotically follows a $\chi^{2}(k)$ distribution where $k$ is the number of elements in $\beta$ and $W\left(\theta_{0}\right)$ is the variance-covariance matrix of $\widehat{\beta}_{s}-\widetilde{\beta}_{s}\left(\theta_{0}\right)$. We can check the allocation of Wald $_{a}$ in the distribution of simulated Wald $_{s} ; s=1, \cdots, S$ where Wald $_{s}$

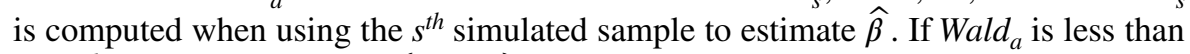
the $c^{\text {th }}$ percentile value of $\left\{\right.$ Wald $\left._{s}\right\}$ sorted from smallest to largest, $H_{0}$ cannot be rejected in a $c \%$ confidence interval; otherwise the model is false. An alternative way is to compute the transformed Mahalanobis Distance (TMD) and compare it with the critical value of $t$ distribution on the $c \%$ confidence interval.

$$
Z=T_{c}\left[\frac{\sqrt{2 \text { Wald }_{a}}-\sqrt{2 k-1}}{\sqrt{2 \text { Wald }_{c}}-\sqrt{2 k-1}}\right]
$$

where $T_{c}$ is the critical value of a one-tail $t$ distribution on the $c \%$ confidence interval.

Generally, a (linearised) DSGE model can be represented as a VARMA or a $\operatorname{VAR}(\infty)$ which can be further represented to a $\operatorname{VAR}(p)$ with a finite order or even a VAR(1) (Dave and DeJong (2007), Wickens (2014)). However, the long-run solution of our model can only be approximated as a VARX with non-stationary lagged endogenous variables $X$ due to nonstationary productivities. Le et al. (2011), Le et al. (2016) and Meenagh et al. (2019) conduct Monte Carlo experiments to find the power of the test as the variables included and the order of the VAR vary. They find that a VAR(1) in 3 endogenous variables typically has good power, while raising the order or the variable number further can boost the power too far for any hope of finding a tractable model that can pass the test. Hence, we typically use a VARX(1) with 2 or 3 variables, combined with the lagged individual productivities as the " $\mathrm{X}$ ".

Given the null hypothesis that the structural model is true, one can back out the structural errors from the model and the actual data and then bootstrap these structural errors to obtain simulated samples. II is also used to estimate the parameters by searching for the parameter values such that the relevant Wald or TMD is smallest.

Le et al. (2011) and Le et al. (2016) conduct Monte Carlo power tests on three testing methods on different models: II, the Likelihood ratio test; and the "unrestricted Wald" test (in which the reduced form VAR on the data sample rather than the VAR from the structural model is bootstrapped). II is found to have far more potential power than the other classical testing methods.

To evaluate the power of II on our model here, we use Monte Carlo experiments to compute the power of the test against parameter mis-estimation. As can be seen in the next section the power of our test here is considerable, giving us a guarantee that our estimates are reasonably close to the truth.

\subsection{The Power of the Test Against Numerical Inaccuracy}

We first generate 500 samples from the true model and the actual data. Then treating each simulated sample from the true model as the observation, we test the false model 
by II and calculate the rejection rate out of the 500 Monte Carlo experiments. Table 2 shows the result of our power test against the false models with mis-estimation where both structural parameters and the AR coefficients of the errors are alternately falsified by $+/-x \%$ each time. The probability of rejecting the false models rises sharply with an increase in the falsity of parameters.

In order to choose a suitable auxiliary model, we carried out Monte Carlo experiments to check the power of different variables being included in the VECM. We can see that power is acceptable with just the two regional GDPs; and rises very sharply when consumption is added. We decided to choose the one with the two regional GDPs where power is slightly weaker but still substantial.

\section{Empirical Analyses}

\subsection{Model Fit}

We test and estimate the regional model using Indirect Inference. Some coefficients such as discount factor, depreciation rate, and growth rate are held fixed on theoretical grounds and the regional tax on innovation $\phi_{2, i j}$ and incentives to innovation $c_{1 i}$ are fixed as well. We also fix parameters such as market shares and some ratios see Table 2. For the elasticity in the labour market, we look for a labour supply elasticity $\left(\frac{1}{\rho_{2 i}}\right)$ in the North that is bigger than in South due to a greater relative abundance of labour and housing. All behavioural parameters are estimated. We now go on to show these results.

The empirical results below show that the regional model is rejected using the calibrated parameters from Meenagh et al. (2010), with a p-value equal to 0, implying no match at all to the data behaviour. That means the national behaviour cannot fit the regional model. Therefore, estimation is necessary. We estimate the regional model and find a set of coefficients can fit the regional data behaviour very well with $p$-value of 0.12. According to the previous Monte Carlo power test, we believe the results trustworthy and also can provide us the reliability of policy implication (See Tables 3, 4, 5).

\subsection{How the Model Behaves in Response to Shocks and Long Run Impacts of Different Policy Changes}

The following graphs show the long run impacts of permanent shocks to different policy variables (tax on labour, tax on firm, UNR, tax on innovation), all of size 0.1 ; also for a productivity shock, taking goods sector in North as an example. We

Table 2 Power test against numerical falsity of parameters- using GDPN and GDPS in the auxiliary model

\begin{tabular}{lccccr}
\hline Parameter Falseness & True & $5 \%$ & $10 \%$ & $15 \%$ & $20 \%$ \\
\hline Rejection Rate at 5\% Level (GDP N and S) & 4.45 & 15.5 & 44.0 & 68.9 & 82.4 \\
Rejection Rate at 5\% Level (GDP N and S, C) & 5.25 & 48.0 & 92.0 & 98.9 & 99.8 \\
\hline
\end{tabular}


Table 3 Structural model coefficients fixed throughout study

\begin{tabular}{llll}
\hline Definition & Parameter & Calibration & Estimation \\
\hline Fixed Coefficients & & & \\
Quarterly discount factor & $\beta$ & 0.985 & FIX \\
Housing depreciation rate & $\delta_{h}$ & 0.015 & FIX \\
Quarterly output growth rate & $g$ & 0.005 & FIX \\
Regional tax on innovation & $\phi_{2, i j}$ & -0.17 & FIX \\
Incentives to innovation & $c_{1 i}$ & 0.06 & FIX \\
Share of goods price in CPI & $\omega$ & 0.7 & FIX \\
Share of housing price in CPI & $\gamma$ & 0.3 & FIX \\
$N_{c i} / N$ & $n 1$ & 0.94 & FIX \\
$N_{h i} / N$ & $n 2$ & 0.06 & FIX \\
$Y c / G D P$ & $g 1$ & 0.94 & FIX \\
$Y h P h / G D P$ & $g 2$ & 0.06 & FIX \\
$Y c / C$ & $c 1$ & 1.732 & FIX \\
$E X / C$ & $c 2$ & 0.361 & FIX \\
$I M / C$ & $c 3$ & 0.369 & FIX \\
$G / C$ & $c 4$ & 0.44 & FIX \\
$E X / Y$ & $b f 1$ & 0.208 & FIX \\
$I M / Y$ & $b f 2$ & 0.214 & FIX \\
\hline
\end{tabular}

Table 4 Structural Model Coefficients: 1986Q1-2019Q4

\begin{tabular}{llll}
\hline Definition & Parameter & Calibration & Estimation \\
\hline Estimated Coefficients & & & \\
Import demand elasticity & $\sigma$ & 1 & 3.2692 \\
Elasticity of substitution $(\mathrm{Cd}, \mathrm{Cf})$ & $\sigma^{F}$ & 0.7 & 7.2505 \\
Risk-premium coefficient & $\psi$ & 0.001 & 0.0064 \\
North & & & \\
CRRA coefficient $(\mathrm{Ct})$ & $\rho_{1 N}$ & 2 & 0.0155 \\
CRRA coefficient $(\mathrm{Nt})$ & $\rho_{2 N}$ & 0.5 & 1.3378 \\
CRRA coefficient $(\mathrm{Ht})$ & $\rho_{h N}$ & 1 & 9.4521 \\
Wage elasticity to union rate & $\delta_{N}$ & 1 & 1.0571 \\
South & & & \\
CRRA coefficient $(\mathrm{Ct})$ & $\rho_{1 S}$ & 2 & 0.0155 \\
CRRA coefficient $(\mathrm{Nt})$ & $\rho_{2 S}$ & 1 & 2.6756 \\
CRRA coefficient $(\mathrm{Ht})$ & $\rho_{h S}$ & 1 & 8.0117 \\
Wage elasticity to union rate & $\delta_{S}$ & 1 & 1.7429 \\
Test Results & & & \\
P-value & & 0 & 0.12 \\
Wald & & 2691.61 & 7.13 \\
T-Wald $\left(G D P_{N}, G D P_{S}\right)$ & 56.60 & 1.04 \\
\hline
\end{tabular}


Table 5 Shocks Process

\begin{tabular}{|c|c|c|c|}
\hline Shock Definition & Parameter & Calibration & Estimation \\
\hline \multicolumn{4}{|l|}{ North } \\
\hline Preference shock & $\rho_{r N}$ & 0.7867 & 0.7763 \\
\hline Real wage shock & $\rho_{l N}$ & 0.9649 & 0.9839 \\
\hline Housing demand shock & $\rho_{h N}$ & 0.9308 & 0.9605 \\
\hline Labour demand shock in goods sector & $\rho_{n c N}$ & 0.9321 & 0.9346 \\
\hline Labour demand shock in housing sector & $\rho_{n h N}$ & 0.9872 & 0.9847 \\
\hline Measurement error in labour demand & $\rho_{m 2 N}$ & 0.9610 & 0.9610 \\
\hline \multicolumn{4}{|l|}{ South } \\
\hline Preference shock & $\rho_{r S}$ & 0.7867 & 0.7763 \\
\hline Real wage shock & $\rho_{l S}$ & 0.9733 & 0.9965 \\
\hline Housing demand shock & $\rho_{h S}$ & 0.9173 & 0.9492 \\
\hline Labour demand shock in goods sector & $\rho_{n c S}$ & 0.9553 & 0.9528 \\
\hline Labour demand shock in housing sector & $\rho_{n h S}$ & 0.9849 & 0.9819 \\
\hline Measurement error in labour demand & $\rho_{m 2 S}$ & 0.9629 & 0.9629 \\
\hline \multicolumn{4}{|l|}{ National shocks } \\
\hline UNR & $\rho_{\text {unr }}$ & 0.9763 & 0.9763 \\
\hline Export shock & $\rho_{e x}$ & 0.9390 & 0.9489 \\
\hline Import shock & $\rho_{i m}$ & 0.7321 & 0.8025 \\
\hline Tax on firm shock & $\rho_{t f}$ & 0.9325 & 0.9325 \\
\hline Tax on labour shock & $\rho_{t l}$ & 0.8781 & 0.8781 \\
\hline Tax on innovation shock & $\rho_{\tau}$ & 0.9608 & 0.9608 \\
\hline Unemployment benefit & $\rho_{u b}$ & 0.9558 & 0.9558 \\
\hline Foreign consumption shock & $\rho_{c^{\star}}$ & 0.9891 & 0.9891 \\
\hline Foreign interest rate shock & $\rho_{r f}$ & 0.9668 & 0.9668 \\
\hline Government spending shock & $\rho_{G}$ & 0.9719 & 0.9354 \\
\hline \multicolumn{4}{|l|}{ Measurement errors } \\
\hline Measurement error in price definition & $\rho_{m 1}$ & 0.9657 & 0.9688 \\
\hline Measurement error in aggregate level 1 & $\rho_{m e 1}$ & 0.6009 & 0.6009 \\
\hline Measurement error in aggregate level 2 & $\rho_{m e 2}$ & 0.9968 & 0.9968 \\
\hline Measurement error in aggregate level 3 & $\rho_{m e 3}$ & 0.9671 & 0.9671 \\
\hline Measurement error in aggregate level 4 & $\rho_{m e 4}$ & 0.9773 & 0.9773 \\
\hline Measurement error in aggregate level 5 & $\rho_{m e 5}$ & 0.9553 & 0.9553 \\
\hline Measurement error in aggregate level 6 & $\rho_{m e 6}$ & 0.9569 & 0.9569 \\
\hline Measurement error in aggregate level 7 & $\rho_{m e 7}$ & 0.9726 & 0.9726 \\
\hline Measurement error in aggregate level 8 & $\rho_{m e 8}$ & 0.9755 & 0.9755 \\
\hline
\end{tabular}

summarise the responses of some key variables below. The impulse response to all temporary shocks of size 0.1 , allowing for their autocorrelated decay over time are shown in Appendix 4.

We begin with a central tax shock (Figs. 5 and 6): a cut of taxes on labour income or consumption, such as income tax and VAT. Because this raises take-home pay in real terms, it leads to a rise in labour supply, driving down real wages and so 


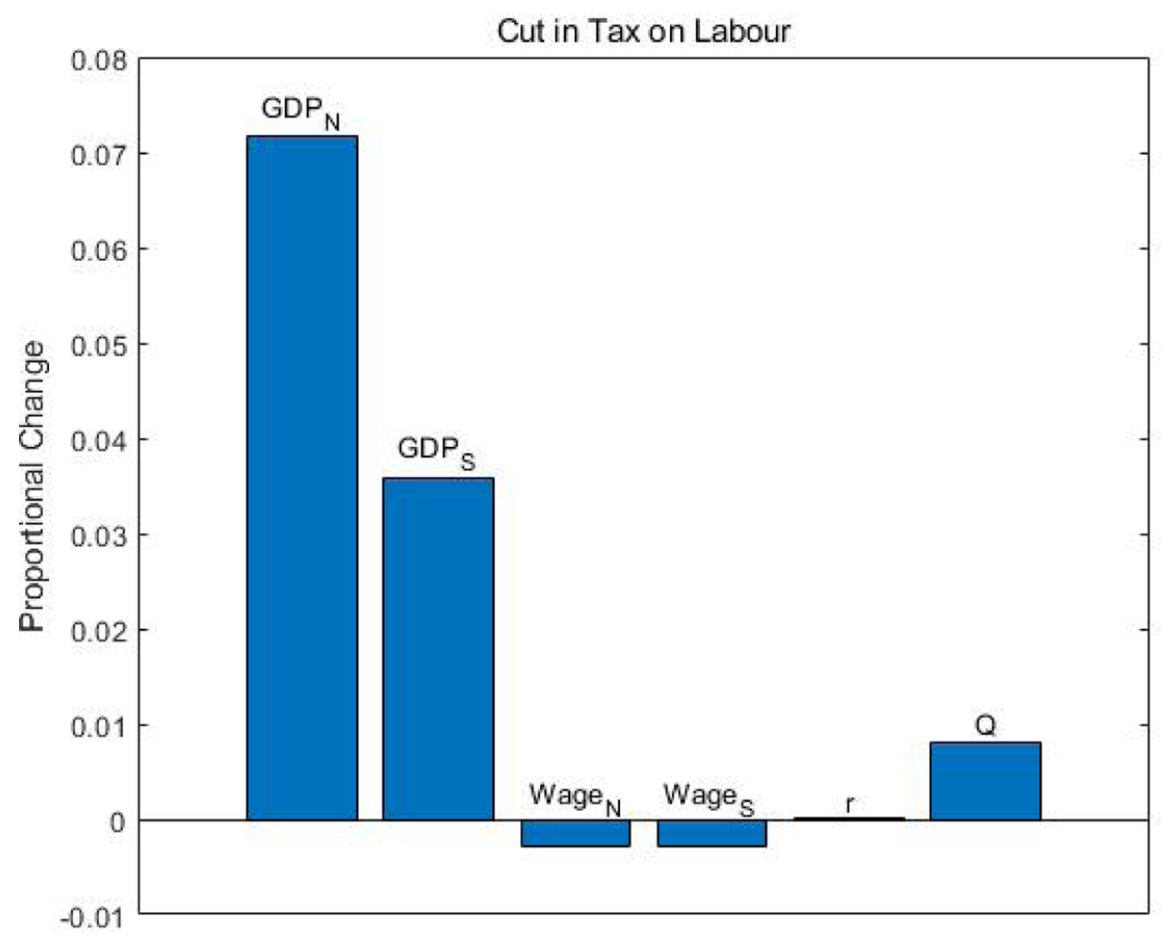

Fig. 5 Permanent Tax on Labour Shock (Standard error: 0.1)

business costs. There is extra output and employment in goods and housing. The real exchange rate depreciates (competitiveness, $\mathrm{Q}$, rises) to enable this extra supply of goods to be sold at home and abroad; this expected depreciation forces up interest rates to maintain uncovered interest parity in the foreign exchange market. The stock of houses rises in both north and south, with demand stimulated by lower house prices to match the increased housing supply. Owing to greater elasticity of labour supply, the Northern economy expands more than the Southern, though both expand.

This description of the transmission of a labour tax cut is mimicked by a cut in the tax on firms' costs, such as corporation tax — see Fig. 6. Here the stimulus in the labour market is to firms' demand for labour as profits rise. This stimulus drives up wages, and so employment and output, from the demand side of the labour market. Other effects that flow from this are essentially the same.

When we turn to our index of labour market regulation (Fig. 7), UNR (the unionisation rate proxies these regulative costs), we find the transmission is the same as for a cut in labour taxes: the fall in costs lowers the wage costs paid by firms (included in wages in the model) for a given level of employment. Wages fall, triggering an employment and output rise from firms' demands. The other effects flow as above in the goods and housing markets. 


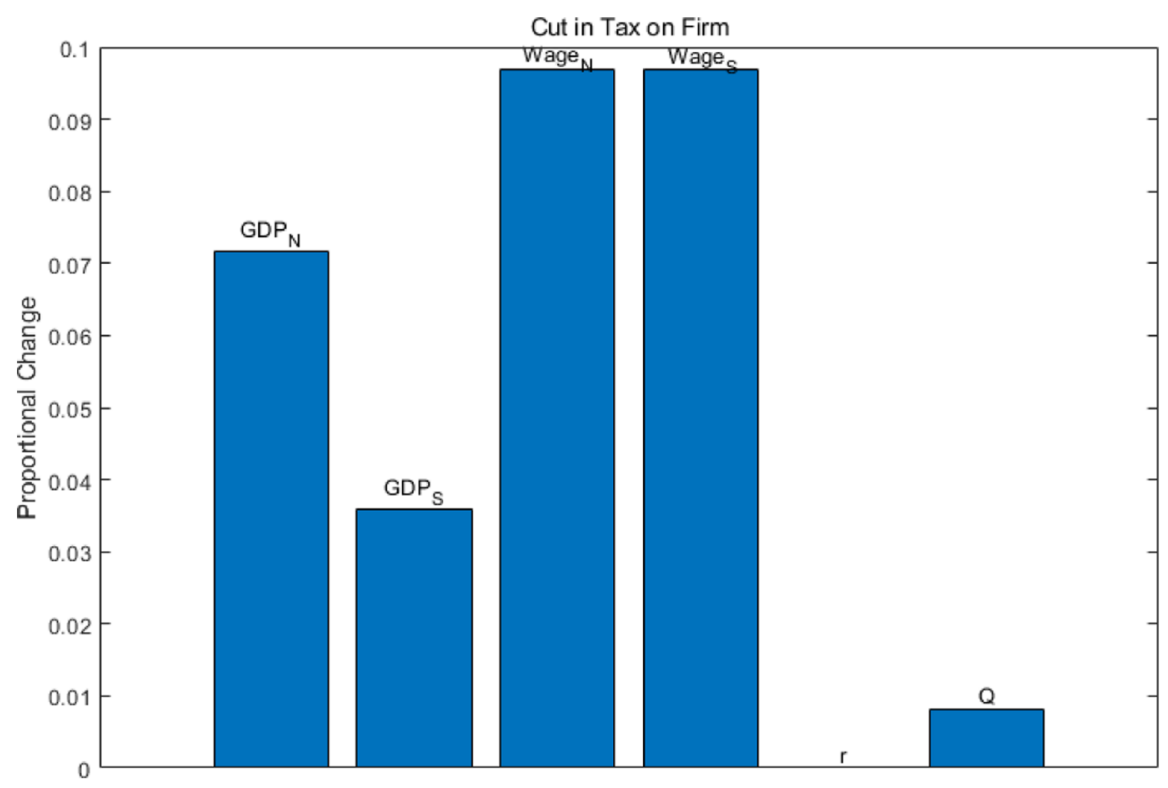

Fig. 6 Permanent Tax on Firm Shock (Standard error: 0.1)

Next, we come to a cut in tax/regulatory-cost for entrepreneurial time (Fig. 8). This cut dies away gradually, following our modelling of the cost process. But each period while it is lower than it was it triggers productivity growth higher than the baseline. Hence there is a cumulative rise in productivity over the period in both North and South. This drives up demand for labour and wages with it, with output stimulated both by this and the rise in productivity. According to the model estimates, the marginal utility of house space falls with rising income, so that faced with much higher productivity of house production, it takes a substantial fall in house prices to induce a matching rise in housing demand. This seems at odds with casual empiricism but it does emerge from the model's estimation. It is this tax cut that has the biggest effects on GDP in both regions, and a steady accompanying rise in competitiveness across the UK.

Finally, Fig. 9 shows the effect of a one-off rise in Northern productivity in the goods sector (but not in housing), such as might be produced by an addition to Northern infrastructure. The transmission is similar to those from the ongoing rise in productivity of the last paragraph, except that it is both confined to the North and one-off rather than continuing. Output, employment and wages rise in the Northern goods sector. The rise in incomes and consumption again induces a fall in housing demand; but as this is smaller than the shift of labour out of housing into the more productive goods sector, driving down house production, house prices must rise to push back on this greater contraction in supply. 


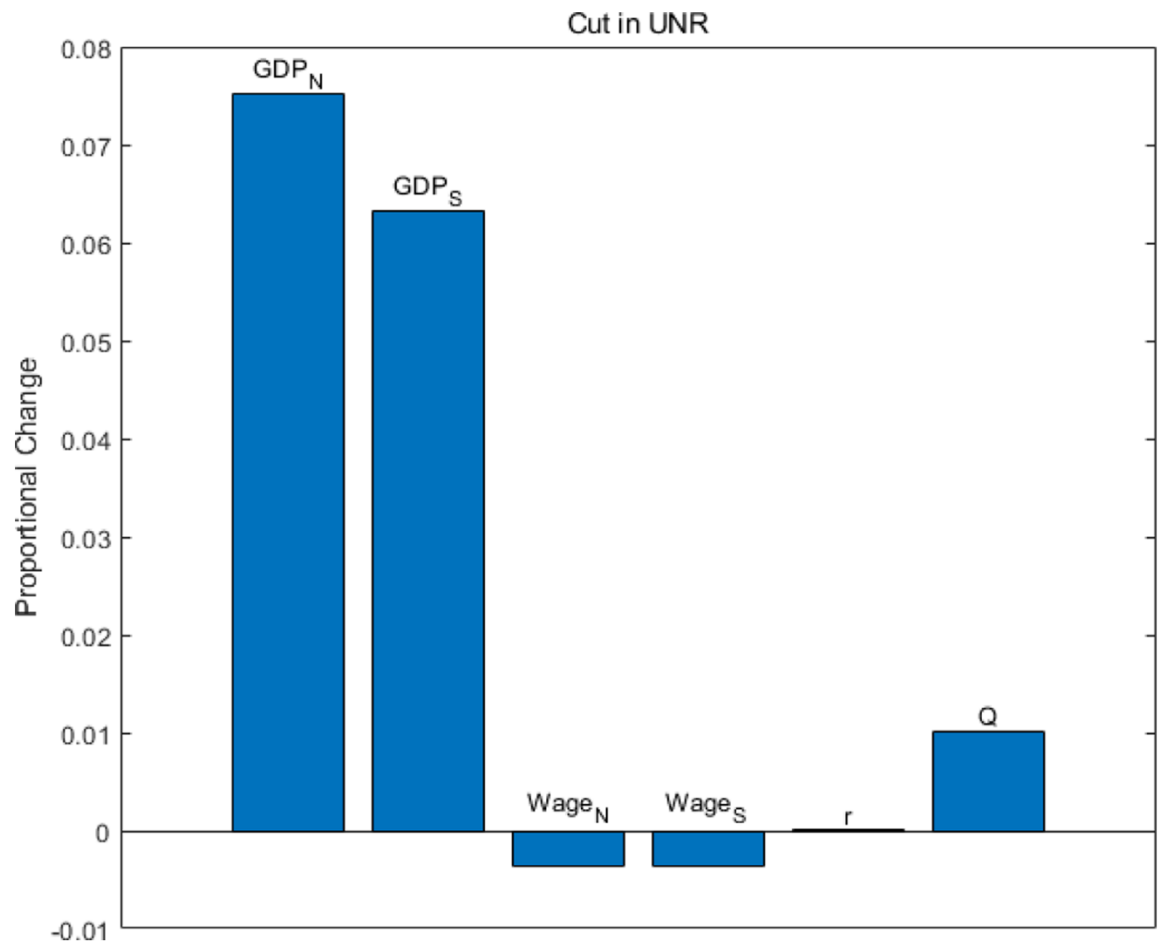

Fig. 7 Permanent UNR Shock (Standard error: 0.1)

\subsection{How the Economy's Shocks have Impacted the Economy and the Regions - Variance Decomposition}

Table 6 shows the variance decomposition of national GDP and GDP in North and South at different horizons (short run; medium run; and long run). We group these different shocks into 9 categories, technology shocks and demand shocks in North and South, regional labour market shocks, tax, regulation and other supply-side policy shocks, international shocks and 'other' shocks. While from a policy viewpoint we naturally focus on tax and supply-side shocks, from a business cycle viewpoint output will be heavily influenced by demand, especially consumption. Under perfect competition with prices set at longrun marginal costs, output will respond to demand through market clearing. Consumption will also affect labour supply and so longrun resource availability. By their effects on imports and the balance of payments they affect the longrun real exchange rate and via this the real wages of households and so again labour supply. The model also implies spillover effects across regions via this transmission mechanism.

From the following table, we can see that demand shocks play a significant major role in the short run and medium run, while technology shocks dominate in the long run. The demand shocks in North contribute 34\% to GDP North variance in the short run, falling to $8 \%$ in the long run. Demand shocks in the South contribute 


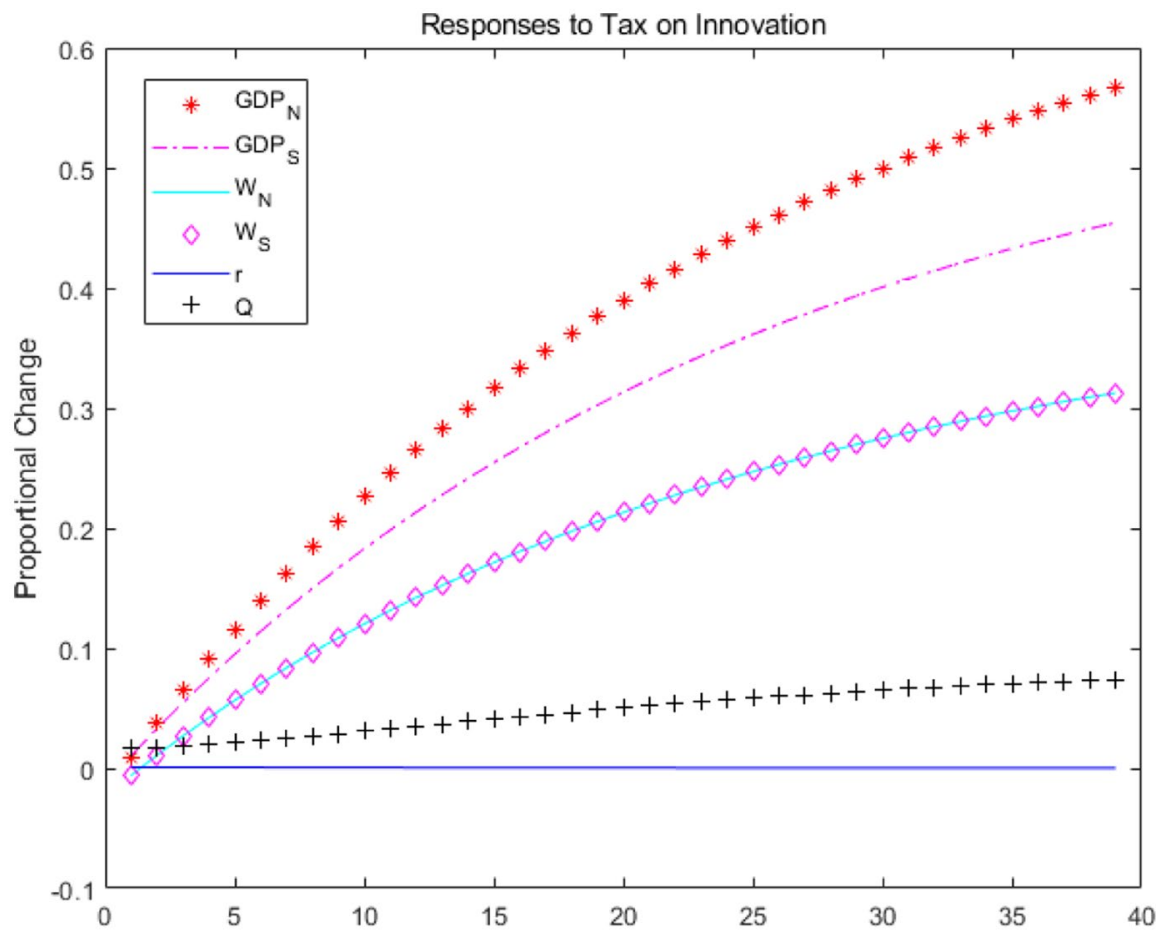

Fig. 8 Tax on Innovation Shock (Standard error: 0.1)

6-36\% of the volatility of GDP South at different horizons. Both $\mathrm{N}$ and S demand shocks spill over considerably across the regional border. Regional labour market shocks account for $12-19 \%$ of long run GDP variance in the North and $8-23 \%$ in the South. The regional technology shocks dominate the volatility of regional GDP in the long run, accounting for 51\% in the North and 57\% in the South, though much less in the short run: only $4 \%$ in the North and $8 \%$ in the South. Tax and supply-side policy shocks explain $20 \%$ of national GDP variance in the short run; but only $6 \%$ in the North and 3\% in the South; this highlights the main thrust of the model, which is that policy reforms have more impact (roughly double) in the North than in the South. The full shocks data is shown in Appendix 3.

\subsection{The Model's Variation over Time Due to Shocks - Historical Decomposition}

Figure 10 below shows how these shocks contributed historically over the sample period to GDP in North and South. What we see here as expected is that the dominant contributor to the evolution of output in North and South is their own productivity shocks. We can identify contributions from supply-side policy shocks, but these are minor compared with the exogenous productivity that we do not explain. 


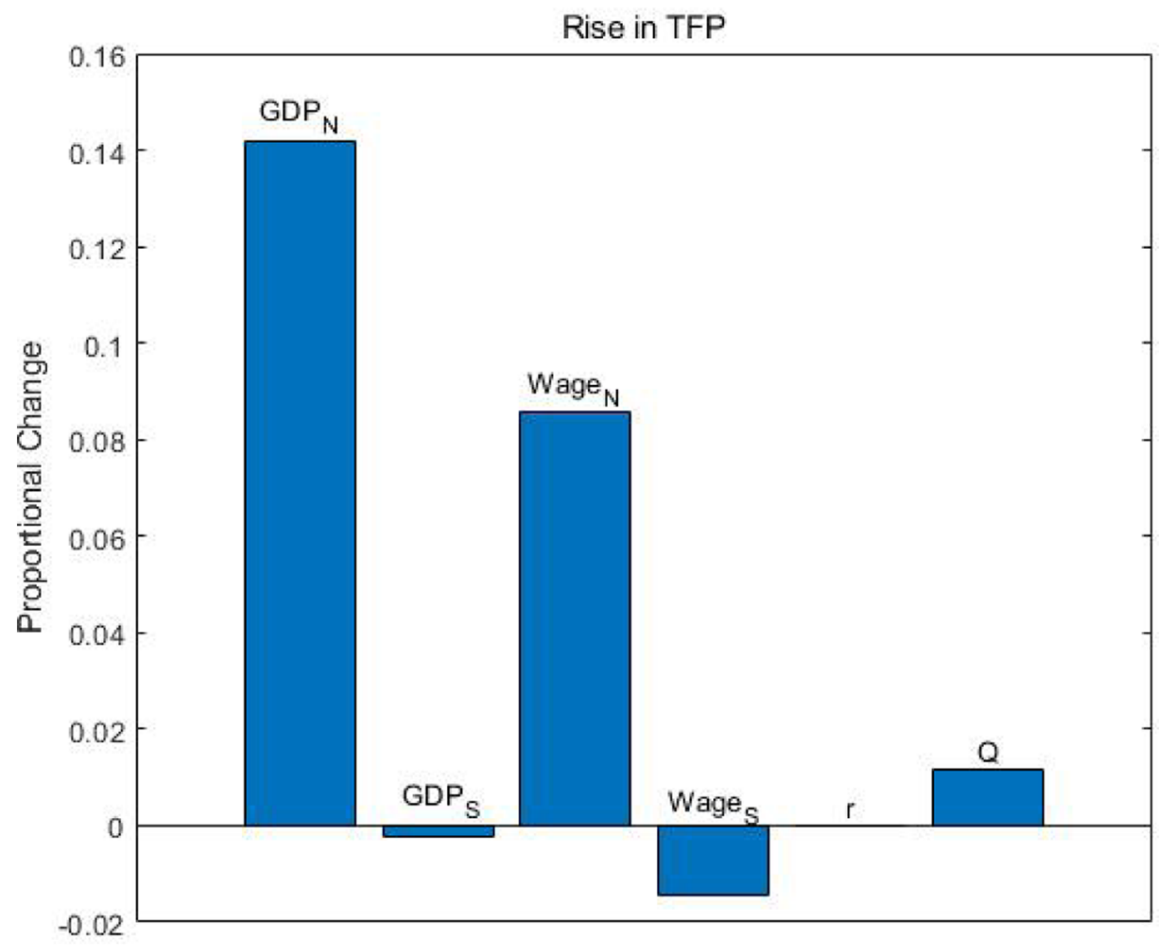

Fig. 9 Productivity Shock in Goods Sector in North (Standard error: 0.1)

Table 6 Variance Decomposition

\begin{tabular}{|c|c|c|c|c|c|c|c|c|c|}
\hline & TFP N & Dem. N & Lab. N & TFP S & Dem. S & Lab. S & Policy & Internat & Other \\
\hline \multicolumn{10}{|c|}{ Short run } \\
\hline GDP & 7.56 & 13.12 & 20.05 & 3.14 & 16.68 & 3.31 & 20.50 & 3.29 & 12.36 \\
\hline GDP N & 4.59 & 34.11 & 12.17 & 0.00 & 37.55 & 0.00 & 6.56 & 1.05 & 3.96 \\
\hline GDP S & 0.00 & 39.62 & 0.01 & 8.06 & 36.85 & 8.45 & 3.51 & 0.56 & 2.94 \\
\hline \multicolumn{10}{|c|}{ Medium run } \\
\hline GDP & 14.82 & 5.66 & 27.37 & 6.17 & 7.13 & 5.37 & 16.36 & 1.60 & 15.51 \\
\hline GDP N & 13.41 & 21.90 & 24.76 & 0.01 & 24.01 & 0.01 & 7.76 & 0.76 & 7.40 \\
\hline GDP S & 0.01 & 24.58 & 0.01 & 22.82 & 22.94 & 19.83 & 4.11 & 0.39 & 5.31 \\
\hline \multicolumn{10}{|c|}{ Long run } \\
\hline GDP & 40.56 & 1.64 & 15.01 & 16.91 & 2.06 & 6.94 & 10.05 & 0.51 & 6.33 \\
\hline GDP N & 51.66 & 8.91 & 19.11 & 0.02 & 9.76 & 0.01 & 5.87 & 0.34 & 4.32 \\
\hline GDP S & 0.02 & 6.58 & 0.01 & 57.92 & 6.14 & 23.76 & 3.34 & 0.12 & 2.11 \\
\hline
\end{tabular}

Dem. Demand shocks; Lab. Labour market shocks; Policy Tax, regulation and other supply-side policy shocks 
We can also see how the variations in regional GDP around this evolving (stochastic) trend were stimulated by demand shocks such as during the financial crisis. What we can see from the analysis above is that productivity movements accumulate over time accounting for the trends in North and South output. Around this 'stochastic' trend, other shocks create business cycle variation. These shocks come from consumer preferences and also labour supply and demand shocks from households and firms respectively. Through all this, policy shocks are crucial in changing the direction of the economy from time to time. But they are few and far between so they do not cause much business cycle variation.
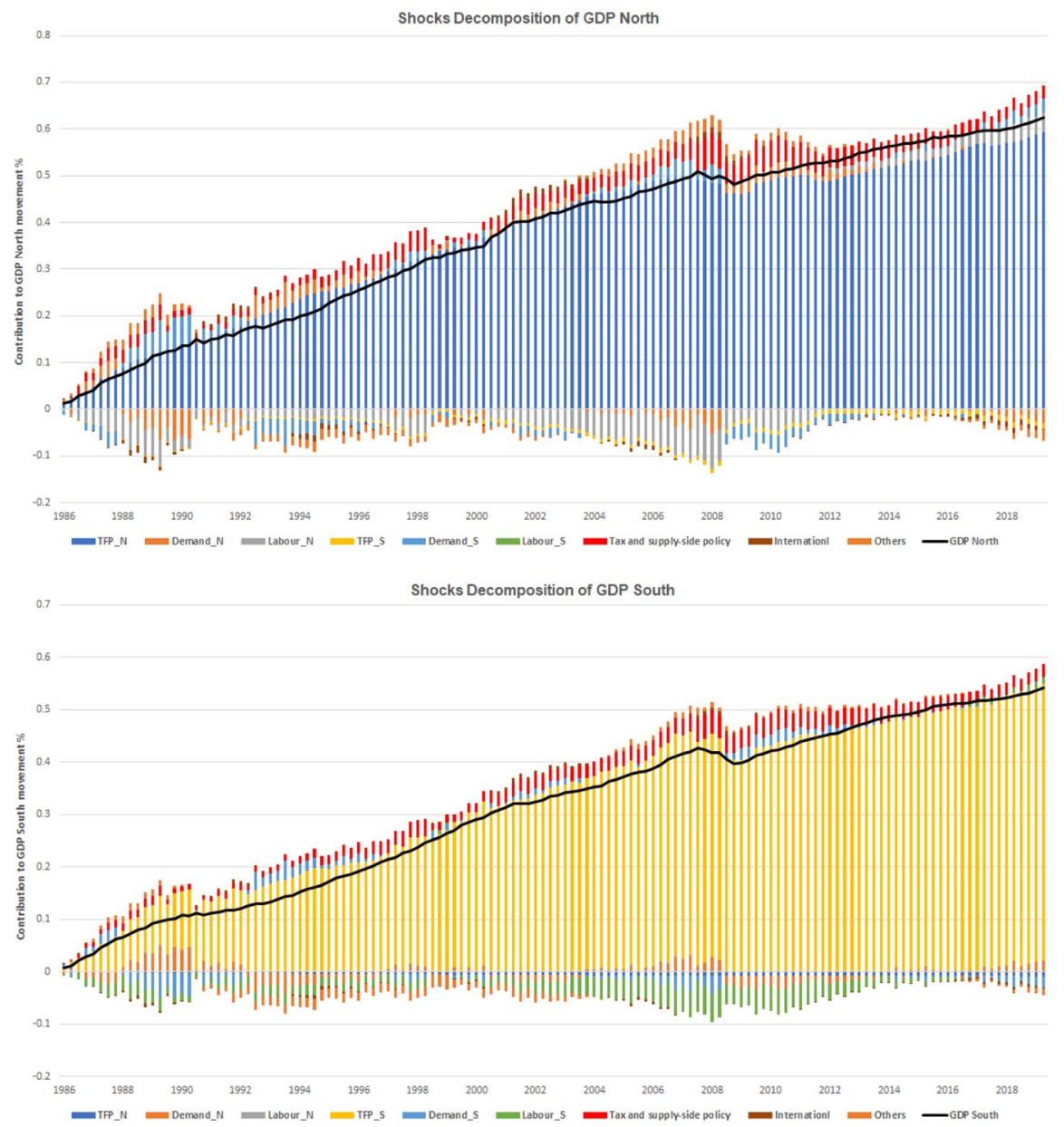

Fig. 10 Shocks Decomposition of GDP in North and South 
Table 7 Long run Effects of different tax/regulative measures on North and South (Each package costed at $£ 10$ billion p.a.)

\begin{tabular}{llc}
\hline Percentage change in & $G D P_{N}$ & $G D P_{S}$ \\
\hline $\begin{array}{l}\text { Cut standard rate of income tax or VAT or other general income/consumption } \\
\text { tax }\end{array}$ & 1.1 & 0.5 \\
Cut Corporation tax rate & 0.8 & 0.4 \\
Cut marginal tax rate and regulative burden on Entrepreneurs/SMEs & 20 & 17 \\
Increase infrastructure spending in North & 1.6 & - \\
\hline
\end{tabular}

\section{Policy Implication}

\subsection{Key Policy Effects and Fiscal Costs}

We can summarise the effects of the policy shocks reviewed in the last section in a Table that shows these long-run effects harmonised around a $£ 10$ billion p.a. fiscal cost (about $0.5 \%$ of GDP) - this Table we placed already as Table 7 at the start, summarising the model's policy effects. What emerges strongly when set out this way is the very large effect per tax cost of regulatory reform and cuts in marginal tax rates on entrepreneurs. The former has no fiscal cost at all; as for the latter the key marginal tax rates are the very top ones, whose tax yield is known to be negligible, with the highest even negative, due to 'Laffer Curve' effects, whereby they stimulate reduction in hours and emigration (Minford and Ashton (1991)). This work reveals that the best way to 'soak the rich' is to keep marginal tax rates on them right down; even though this might seem politically difficult, it would 'play well' in the politically important North because of its effects on growth. If accompanied by other general tax cuts, the effects would be larger still and politically highly palatable. For example, a general income tax cut of $£ 10$ billion would be fiscally affordable in the long run, as it would raise GDP by $0.8 \%$, bringing in extra tax of about $£ 10$ billion (the average marginal tax rate in the UK is about 0.6 ); hence in the long run roughly paying for itself. The long run tax yield of regulatory reform plus cuts in top marginal rates is far higher still: with a boost to GDP of about $15 \%$, the gain in tax is an astonishing $£ 180$ billion.

In gauging the effect of infrastructure spending of $£ 10$ billion per year, we have assumed that this adds to the capital stock by $£ 100$ billion over ten years; according to the ONS' latest (2019) Blue Book, the UK ratio of capital to GDP is 2.0. Spent across the UK in proportion to GDP, this new spending would raise the capital stock by $2.5 \%$; the capital income share of 0.3 is also the elasticity of productivity to capital in a Cobb-Douglas production function (assumed to underlie our labour-only specification); hence productivity in response would rise by $0.8 \%$. Applied solely to the North, with half the GDP and capital stock, the productivity rise would be double. 
Table 8 A fiscal stimulus package costing ( $£ 100$ billion p.a.

\begin{tabular}{ll}
\hline Tax Cuts & Amount \\
\hline Cut corporation tax by 10\% & $£ 32 \mathrm{bn}$ \\
Abolish the very top additional 5\% rate & $£ 1 \mathrm{bn}$ \\
Cut the top rate of income tax to 30\% & $£ 15 \mathrm{bn}$ \\
Cut the standard rate of income tax by 5\% & $£ 28 \mathrm{bn}$ \\
Total Tax Cuts & $£ 76 \mathrm{bn}$ \\
Public Spending & $£ 24 \mathrm{bn}$ \\
Total Package & $£ 100 \mathrm{bn}$ \\
\hline
\end{tabular}

${ }^{\mathrm{a}}$ Representing a weighted average tax cut across all income of about $15 \%$.

${ }^{\mathrm{b}}$ On public services and infrastructure.

Table 9 Long run Effects on North and South of the package of Table 8 measures (total package costed at $£ 100$ billion p.a.)

\begin{tabular}{llll}
\hline Percentage change in & $G D P_{N}$ & $G D P_{S}$ & $G D P$ \\
\hline $\begin{array}{l}\text { Cut standard rate of income tax or VAT or other general income/con- } \\
\quad \text { sumption tax }\end{array}$ & 3.3 & 1.5 & 2.4 \\
Cut Corporation tax rate & 2.4 & 1.2 & 1.8 \\
Cut marginal tax rate and regulative burden on Entrepreneurs/SMEs & 20 & 17 & 18.5 \\
Increase infrastructure spending in North & 3.8 & - & 1.9 \\
Total & 29.5 & 19.2 & 24.6 \\
\hline
\end{tabular}

\subsection{The Effects of a Supply-side Reform Package on Growth and Regional Inequality}

We now show the total effects of a wide-ranging supply-side reform package costing $5 \%$ of GDP ( $£ 100$ billion p.a.) and made up as follows (See Table 8):

Applying these amounts to the multipliers shown in the Table 7 above for $£ 10$ billion each, we can construct the following Table 9 of the full Package effects:

We can see that the package generates higher GDP of $25 \%$, an extra $2.3 \%$ growth p.a., with nearly $3 \%$ p.a. greater growth in the North, so reducing the North-South gap by $8 \%$. Clearly this is levelling-up of a generally beneficial kind.

One question that will naturally be asked is whether this package, which in the short run must add to debt, damages the government's solvency. A simple way to analyse this is to use the proposition that a government is solvent if it generates a primary surplus in the long run, so ensuring that the long run growth rate of debt is less than the real interest rate (see Minford and Peel (2019), pp 158-162) ${ }^{5}$. The

\footnotetext{
5 This can be sen as follows. Solvency can be defined as where the present value of the public debt, $b$, converges to zero in infinite time: $b_{T} /(1+r)^{T} \rightarrow 0$ as $T \rightarrow \infty$. In other words, debt grows at less than the real rate of interest, $r$. Through the budget constraint, $\Delta b_{t+1}=r b_{t}-s$ where $s$ is the primary surplus. Hence the growth rate of the debt, $g=\Delta b_{t+1} / b_{t}=r-s / b_{t}$. So solvency implies $s$ must be positive, i.e. there must be a primary surplus. the speed of convergence is given by $s / b$.
} 
primary surplus $=\tau y-g y$, where $\tau$ is the average tax rate and $g$ is the share of spending other than debt interest. Note that our package does not affect $g y$ in the long run since spending apart from the direct package itself is unaffected; however, the ongoing package has a direct negative effect on the surplus of $5 \%$ of GDP.

Now consider the effect of the package on tax revenue independently of this direct effect, $\delta(\tau y) / \delta$ Package.

We can write $[\delta(\tau y) / \delta$ Package $] / y=[(y \delta \tau / \delta y+\tau) \delta y / \delta$ Package $] / y=[(\eta+1) \tau$ $(\delta y / \delta$ Package $)] / y$. where $\eta$ is the elasticity of the net tax rate to GDP, around 2 in the $\mathrm{UK}^{6}$. The net tax rate (taxes less welfare benefits)/GDP is about 0.2. As we have seen, the effect of the package on long run GDP (over a decade, we take it) is about 0.25 ; hence this effect on tax revenue is $15 \%$ of GDP. So, subtracting from this the direct package cost, we obtain the overall long run effect of the package on the primary surplus of about $10 \%$ of GDP, a healthy extra contribution to solvency.

We can gauge the size of this contribution by $s / b$, measuring the speed of downwards convergence of the debt ratio, in effect to some 'safe' optimal value. To do this we need to divide $s / y$ by the long run debt ratio; we can compute the movement of this last with some simple arithmetic. Assume the pre-package debt and GDP were both 100 in baseline prices, making a 100\% debt ratio. We then note the debt ratio would move upwards by $5 \times 10$ (10 years of the extra spending), which is $50 \%$. However annual net taxes would rise by 8 per year from an average of 20 to the new average tax rate of $0.275(0.2+$ half the rise of 0.15$)$ times the average new GDP of 112, making total average net revenue of 28 per year; this over ten years reduces the debt ratio by $80 \%$, which net of the package cost lowers it to $70 \%$, terminal GDP constant. Finally terminal GDP would be $24 \%$ higher, reducing the terminal debt/ GDP ratio to $56 \%$, compared with the baseline $100 \%$. So the package increases the primary surplus by $18 \%$ of debt $(10 \% / 0.56)$, speeding up the debt ratio's downwards convergence to safety. In effect the package pays for itself through its effect on growth and net taxes.

\footnotetext{
${ }^{6}$ This comes about as follows. The average (net of benefit) tax yield is 0.20 . This average rate consists about half of income taxes and half of expenditure taxes (mainly VAT). For income taxes, the top 50\% of income earners have $75 \%$ of income and pay $88.4 \%$ of income tax. Their average tax rate is about $14 \%$. For those in the bottom $50 \%$, with $25 \%$ of income, they pay negative tax of about $9 \%$ of their income (Source: Table 2.7 of HMRC Income Tax Statistics).

So the average net tax rate on income is $(0.75$ (the share of income of top $50 \%) * 14 \%)-(0.25 * 9 \%)=$ $8 \%$. The average tax rate on other (indirect) taxes would then be about $12 \%$, so that the total net tax rate is about $20 \%=8 \%+12 \%$. This is in line with the calculated average net tax rate.

This average net rate, ART, is to be compared with the marginal tax rate. For income tax this is around 0.4 (for some it will be higher and for benefit recipients it is close to 0.7 ; but for very many it is the top band rate of 0.4, while for minorities it is less or much more) and for indirect taxes around 0.2 (the marginal VAT rate). Hence on $£ 100$ of income extra total tax will be $£ 60$, a marginal tax rate, MRT, of $60 \%$. The elasticity of tax revenue to income is MRT/ART, which is therefore about 3 . This implies that the ART rises by $2 \%$ for every $1 \%$ rise in GDP - an elasticity of the ART of 2 - while tax receipts net of benefits rise by $3 \%$ for every $1 \%$ rise in GDP - a tax total elasticity of 3 .
} 


\section{Conclusion}

We set up a two-region model to study the policy challenge of bringing the North's income up to the level of the South in the UK. The model focuses on labour costs as the driver of output gains through the international competitiveness channel; and also on entrepreneurial innovation responses to tax and regulation incentives. The empirical results show that the regional model behaviour fits the regional UK data behaviour over the period of 1986Q1 and 2019Q4 by using the demanding Indirect Inference method; they reveal important differences in regional response parameters. We also carry out a Monte Carlo power test, which shows the empirical results we obtain are trustworthy and can provide us a reliable guide for policy reform.

This paper suggests a policy solution for the problem of relatively slow growth in the North. The empirical results from this model suggest that cutting taxes and easing regulation across the whole economy has big effects on innovation across the economy, with the bigger effect on GDP in the North. Also that in terms of competitiveness effects it primarily benefits the Northern economy because it has a higher relative supply elasticity of labour: it is relatively labour-abundant. The model's Impulse Response Functions show that in response to tax cuts and labour market reforms GDP in the North increases almost twice as much as GDP in the South. Given that a broad programme of tax cuts and regulatory reform would more than pay for itself in the long run, it must be considered as a highly attractive political agenda. In the longer run, as entrepreneurial activity spreads across the North as it has in the South, innovation in the North should also catch up with that in the South.

To put the matter in concrete terms, this work suggests that Northern 'catch-up' is a two part process. In the first part, Northern competitiveness is raised by a general supply-side programme of tax cuts, assisted by a specific programme of more northern infrastructure and related programmes like free ports, creating successful industries across the region. In the second, entrepreneurial innovation is stimulated with a broad pro-enterprise programme, pushing it towards par with the traditionally entrepreneurial South.

\section{Appendix 1}

\section{Linearised Model}

\section{Regional Level}

Regional Goods Sector Regional Output:

$$
\ln Y_{c i, t}=\alpha \ln N_{c i, t}+\ln A_{c i, t}
$$

Regional Consumption:

$$
r_{t}=\rho_{1 i}\left(\ln C_{i, t+1}-\ln C_{i, t}\right)+\left(\varepsilon_{i, t+1}^{r}-\varepsilon_{i, t}^{r}\right)
$$

Regional Labour Demand - Goods Sector: 


$$
\ln N_{c i, t}=\ln Y_{c i, t}-\left(w_{i, t}+T f_{t}-\ln p_{t}\right)+\varepsilon_{i, t}^{n c}
$$

Definition of Price of Goods:

$$
\ln p_{t}=-[(1-\omega) /(1-\gamma)] \ln Q_{t}-[\gamma /(1-\gamma)] \ln p_{h, t}+\varepsilon_{i, t}^{m 1}
$$

Regional Housing Sector Regional Housing Supply:

$$
\ln Y_{h i, t}=\alpha \ln N_{h i, t}+\ln A_{h i, t}
$$

Regional Housing Demand:

$$
A \rho_{h i} \ln H_{i, t}=\left(\rho_{1 i} \ln C_{i, t}-\ln p_{h i, t}\right)-\beta\left(1-\delta_{h}\right)\left[\left(\rho_{1 i} \ln C_{i, t+1}-\ln p_{h i, t+1}\right)+\left(\varepsilon_{i, t}^{r}-\varepsilon_{i, t+1}^{r}\right)\right]+A \varepsilon_{i, t}^{h}
$$

where $A=1-\beta\left(1-\delta_{h}\right)$

Regional Housing Price:

$$
\ln Y_{h i, t}=\frac{H_{i}}{Y_{h i}} \ln H_{i, t}-\left(1-\delta_{h}\right) \frac{H_{i}}{Y_{h i}} \ln H_{i, t-1}
$$

Regional Labour Demand- Housing Sector:

$$
\ln N_{h i, t}=\ln Y_{h i, t}-\left(w_{i, t}+T f_{t}-\ln p_{h i, t}\right)+\varepsilon_{i, t}^{n h}
$$

Regional Labour Market Total Regional Labour Demand $=$ Housing Sector + Goods Sector:

$$
\ln N_{i, t}=\frac{N_{c i}}{N_{i}} \ln N_{c i, t}+\frac{N_{h i}}{N_{i}} \ln N_{h i, t}+\varepsilon_{i, t}^{m 2}
$$

Total Regional Labour Supply:

$$
\ln w_{i, t}=\gamma\left(\ln p_{h i t}-\ln p_{h t}\right)+\rho_{2 i} \ln N_{i, t}+\rho_{1 i} l n C_{i, t}+\rho_{2 i} 2 c_{1 i} \tau_{t}^{\prime}+T l_{t}+U B_{t}+\delta_{i} u n r_{t}+\varepsilon_{i, t}^{l}
$$

\section{National Level}

National Consumption:

$$
\ln C_{t}=\omega_{N} \ln C_{N, t}+\omega_{S} \ln C_{S, t}+\varepsilon_{t}^{m e 1}
$$

National Housing Price:

$$
\ln p_{h, t}=\left(\omega_{N} \ln p_{h N, t}+\omega_{S} \ln p_{h S, t}\right) / 2+\varepsilon_{t}^{m e 2}
$$

National Labour Demand -Goods: 


$$
\ln N_{c, t}=\omega_{N} \ln N_{c N, t}+\omega_{S} \ln N_{c S, t}+\varepsilon_{t}^{m e 3}
$$

where $\omega_{N}=0.58, \omega_{S}=0.42$;

National Labour Demand - Housing:

$$
\ln N_{h, t}=\omega_{h N} \ln N_{h N, t}+\omega_{h S} \ln N_{h S, t}+\varepsilon_{t}^{m e 4}
$$

where $\omega_{h N}=0.66, \omega_{h S}=0.34$;

GDP North:

$$
\ln G D P_{N, t}=\omega_{c} \ln Y_{c N, t}+\omega_{h} p_{h N, t} \ln Y_{h N, t}+\varepsilon_{t}^{m e 5}
$$

GDP South:

$$
\ln G D P_{S, t}=\omega_{c} \ln Y_{c S, t}+\omega_{h} p_{h S, t} \ln Y_{h S, t}+\varepsilon_{t}^{m e 6}
$$

where $\omega_{c}=0.94, \omega_{h}=0.06$;

Total GDP:

$$
\ln G D P_{t}=\omega_{N} \ln G D P_{N, t}+\omega_{S} \ln G D P_{S, t}+\varepsilon_{t}^{m e 7}
$$

National Goods Output:

$$
\ln Y_{c, t}=\omega_{N} \ln Y_{c N, t}+\omega_{S} \ln Y_{c S, t}+\varepsilon_{t}^{m e 8}
$$

Net Export:

$$
\ln C_{t}=\frac{\bar{Y}_{c}}{\bar{C}} \ln Y_{c, t}-\frac{E X}{\bar{C}} \ln E X_{t}+\frac{I M}{\bar{C}} \ln I M_{t}-\frac{\bar{G}}{\bar{C}} \ln G_{t}
$$

Export Demand:

$$
\ln E X_{t}=\ln \tilde{C}_{t}^{\star}+\sigma^{F} \frac{1}{\omega} \ln Q_{t}+e_{X, t}
$$

Import Demand:

$$
\ln I M_{t}=\ln C_{t}-\sigma \ln Q_{t}+e_{M, t}
$$

UIP:

$$
\ln Q_{t}=E_{t} \ln Q_{t+1}+r_{t}^{f}-r_{t}+\psi \tilde{w}_{t-1}^{f}+\rho_{t}
$$

Risk-Premium:

$$
\rho_{t}=-\psi \tilde{f} \tilde{b}_{t}
$$

Balance of Payment: 


$$
\Delta b_{t+1}^{f}=\left(r_{t}^{f}-g\right) \tilde{b}_{t}^{f}+\left(\frac{1}{1+g}\right)\left(\frac{E X}{Y} \ln E X_{t}-\frac{E X}{Y} \ln Q_{t}-\frac{I M}{Y} \ln I M_{t}\right)
$$

\section{Shock Process}

Regional Productivity Shocks in Goods and Housing sector:

$$
\begin{aligned}
& \Delta \ln A_{c i, t}=\phi_{2, c i} \tau_{t-1}^{\prime}+\varepsilon_{c i, t}^{A} \\
& \Delta \ln A_{h i, t}=\phi_{2, h i} \tau_{t-1}^{\prime}+\varepsilon_{h i, t}^{A}
\end{aligned}
$$

Other Regional Shocks:

$$
\begin{aligned}
& \varepsilon_{i, t}^{r}=\rho_{r i} \varepsilon_{i, t}^{r}+v_{i, t}^{r} \\
& \varepsilon_{i, t}^{h}=\rho_{h i} \varepsilon_{i, t}^{h}+v_{i, t}^{h} \\
& \varepsilon_{i, t}^{l}=\rho_{l i} \varepsilon_{i, t}^{l}+v_{i, t}^{l} \\
& \varepsilon_{i, t}^{n j}=\rho_{n c j} \varepsilon_{i, t}^{n j}+v_{i, t}^{n j}
\end{aligned}
$$

National Shocks:

$$
\begin{gathered}
\tau_{t}^{\prime}=\rho_{\tau} \tau_{t-1}^{\prime}+v_{t}^{\tau} \\
r_{t}^{f}=\rho_{r f} r_{t-1}^{f}+v_{t}^{r f} \\
e_{X, t}=\rho_{e x} e_{X, t-1}+v_{t}^{e x} \\
e_{M, t}=\rho_{i m} e_{M, t-1}+v_{t}^{i m} \\
T l_{t}=\rho_{t l} T l_{t-1}+v_{t}^{t l} \\
T f_{, t}=\rho_{t f} T f_{t-1}+v_{t}^{t f} \\
U B_{t}=\rho_{u b} U B_{t-1}+v_{t}^{u b} \\
\ln C_{t}^{\star}=\rho_{c^{\star}} \ln C_{t-1}^{\star}+v_{t}^{c^{\star}}
\end{gathered}
$$




$$
\begin{gathered}
\ln G_{t}=\rho_{G} \ln G_{t-1}+v_{t}^{G} \\
u n r_{t}=\rho_{u n r} u n r_{t-1}+v_{t}^{u n r}
\end{gathered}
$$

Measurement Errors:

$$
\varepsilon_{i, t}^{m e}=\rho_{m e} \varepsilon_{i, t}^{m e}+v_{i, t}^{m e}
$$

\section{Appendix 2}

\section{Data}

The data sample period we used is from 1986Q1 to 2019Q4. Table below shows all definitions and sources of data used in this paper. Most of UK data are from the UK Office of National Statistics (ONS), housing data are from the UK Land Registry. Some tax data and regulations are from HM Revenue and Customs (HMRC) and Official labour market statistics (NOMIS). Other data are from International Monetary Fund (IMF), Organisation for Economic Cooperation and Development (OECD), World Band (WB) and FRED. Some regional data do not have the full

\begin{tabular}{|c|c|c|}
\hline Symbol & Definition and Description & Source \\
\hline \multicolumn{3}{|c|}{ Regional Data } \\
\hline$G D P_{N} G D P_{S}$ & $\begin{array}{l}\text { Regional Total Output (Gross domestic product; Weighted } \\
\text { average in } \mathrm{N} \text { and } \mathrm{S} \text { ) }\end{array}$ & ONS \\
\hline$Y_{c N} Y_{c S}$ & $\begin{array}{l}\text { Regional Output in Goods Sector (Non construction sector; } \\
\text { Weighted average in N and S) }\end{array}$ & ONS \\
\hline$Y_{h N} Y_{h S}$ & $\begin{array}{l}\text { Regional Output in Housing Sector (Construction sector; } \\
\text { Weighted average in N and S) }\end{array}$ & ONS \\
\hline$C_{N} C_{S}$ & Regional Consumption (Weighted average in $\mathrm{N}$ and $\mathrm{S}$ ) & ONS \\
\hline$H_{N} H_{S}$ & $\begin{array}{l}\text { Regional Housing Demand (No. of residential property sales; } \\
\text { Weighted average in N and S) }\end{array}$ & Land Registry \\
\hline$N_{N} N_{S}$ & $\begin{array}{l}\text { Regional Employment (No. of people in employment; } \\
\text { Weighted average in N and S) }\end{array}$ & ONS \\
\hline$N_{c N} N_{c S}$ & $\begin{array}{l}\text { Regional Employment in Goods Sector (Weighted average in } \\
\mathrm{N} \text { and S) }\end{array}$ & Model implied \\
\hline$N_{h N} N_{h S}$ & $\begin{array}{l}\text { Regional Employment in Housing Sector (Weighted average } \\
\text { in N and S) }\end{array}$ & Model implied \\
\hline$p_{h N} p_{h S}$ & $\begin{array}{l}\text { Regional Housing Price (Mean price paid by region; } \\
\text { Weighted average in } \mathrm{N} \text { and } \mathrm{S} \text { ) }\end{array}$ & Land Registry \\
\hline$w_{N} w_{S}$ & $\begin{array}{l}\text { Regional Wage (Average weekly earning; Weighted average } \\
\text { in N and S) }\end{array}$ & ONS \\
\hline \multicolumn{3}{|l|}{ National Data } \\
\hline$G D P$ & National Output (Gross domestic product) & ONS \\
\hline
\end{tabular}
sample, but we know the national data, so we fill in the gap according to the growth rate we get from the national data. 


\begin{tabular}{|c|c|c|}
\hline Symbol & Definition and Description & Source \\
\hline $\bar{C}$ & $\begin{array}{l}\text { National Consumption (Household final consumption } \\
\text { expenditure by households) }\end{array}$ & ONS \\
\hline$C^{*}$ & $\begin{array}{l}\text { Foreign Consumption Demand (Net trade in goods and } \\
\text { services) }\end{array}$ & WB \\
\hline IM & Imports (UK total trade of imports) & ONS \\
\hline EX & Exports (UK total trade of exports) & ONS \\
\hline$N$ & National Employment (No. of people in employment) & ONS \\
\hline$b^{f}$ & Net Foreign Assets (International investment postion) & ONS \\
\hline$w$ & National Wage (Average weely earning) & ONS \\
\hline$p$ & Price of Goods (Price of goods=Domestic goods price/CPI) & Model implied \\
\hline$p_{h}$ & Price of Housing (Mean price by country) & Land Registry \\
\hline$p^{f}$ & $\begin{array}{l}\text { Price of Foreign Goods (Weighted average of CPI in US, } \\
\text { Germany and Japan) }\end{array}$ & IMF \\
\hline$R$ & $\begin{array}{l}\text { Domestic Nominal Interest Rate ( } 3 \text { Month interbank rates for } \\
\text { the UK) }\end{array}$ & FRED \\
\hline$r$ & $\begin{array}{l}\text { Domestic Real Interest Rate (Nominal interest rate minus one } \\
\text { period ahead inflation) }\end{array}$ & Model implied \\
\hline$R^{f}$ & $\begin{array}{l}\text { Foreign Nominal Interest Rate (Weighted average of 3-month } \\
\text { discount rates in US, Germany and Japan) }\end{array}$ & IMF \\
\hline$r^{f}$ & $\begin{array}{l}\text { Foreign Real Interest Rate (Foreign interest rate minus one } \\
\text { period ahead foreign inflation) }\end{array}$ & Model implied \\
\hline$Q$ & Term of Trade (Calculated from $\left.E p^{f} / p\right)$ & Model implied \\
\hline \multicolumn{3}{|c|}{ Taxes and Regulations } \\
\hline$T l$ & $\begin{array}{l}\text { Tax on Labour (Sum of basic income tax rate, NI employee's } \\
\text { rate, tax on general income and consumption ) }\end{array}$ & HMRC \\
\hline$T f$ & Tax on Firm (NI contribution rate by employer) & HMRC \\
\hline unr & Trade Union Membership Rate in the UK & ONS \\
\hline$U B$ & Unemployment Benefit (Jobseeker's Allowance flows) & NOMIS \\
\hline$C C B$ & $\begin{array}{l}\text { Collective Bargaining Coverage (Percentage of employees } \\
\text { with the right to bargain) }\end{array}$ & OECD \\
\hline$\tau^{\prime}$ & $\begin{array}{l}\text { Tax on Innovation (Equal weighted average of income tax rate } \\
\text { and corporation rate times bargaining power with the union } \\
\left.\left(C C B^{*} u n r\right)\right)\end{array}$ & Model implied \\
\hline
\end{tabular}

\section{Appendix 3}

\section{Model Shocks and Innovations}

\section{Model Shocks}

See Figs. 11 and 12 

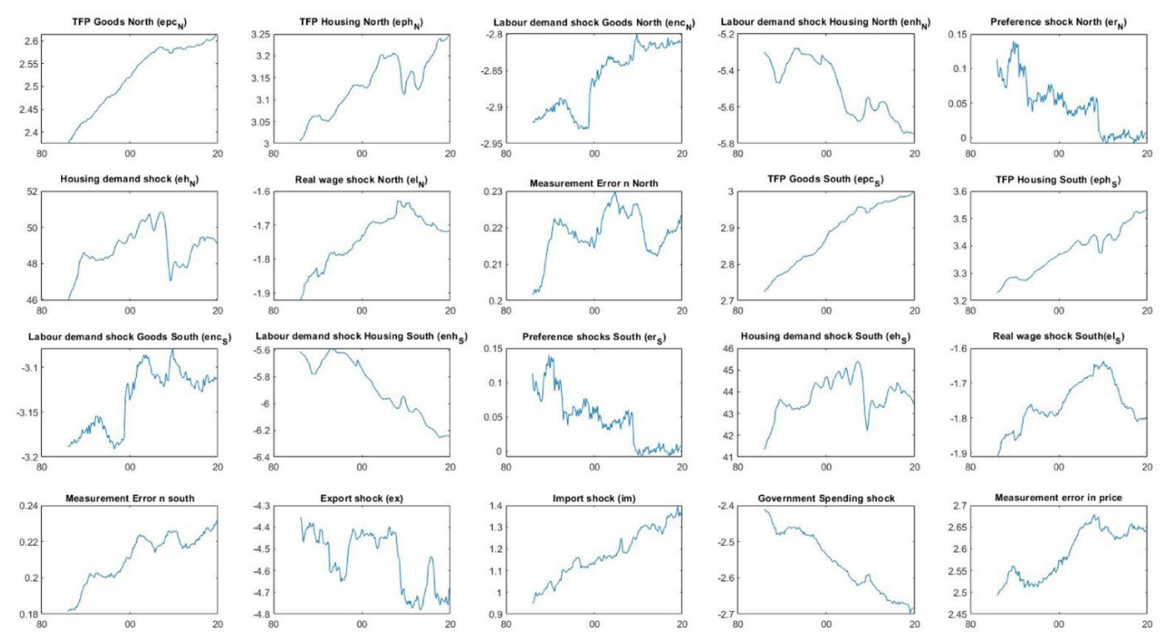

Fig. 11 Model Residuals
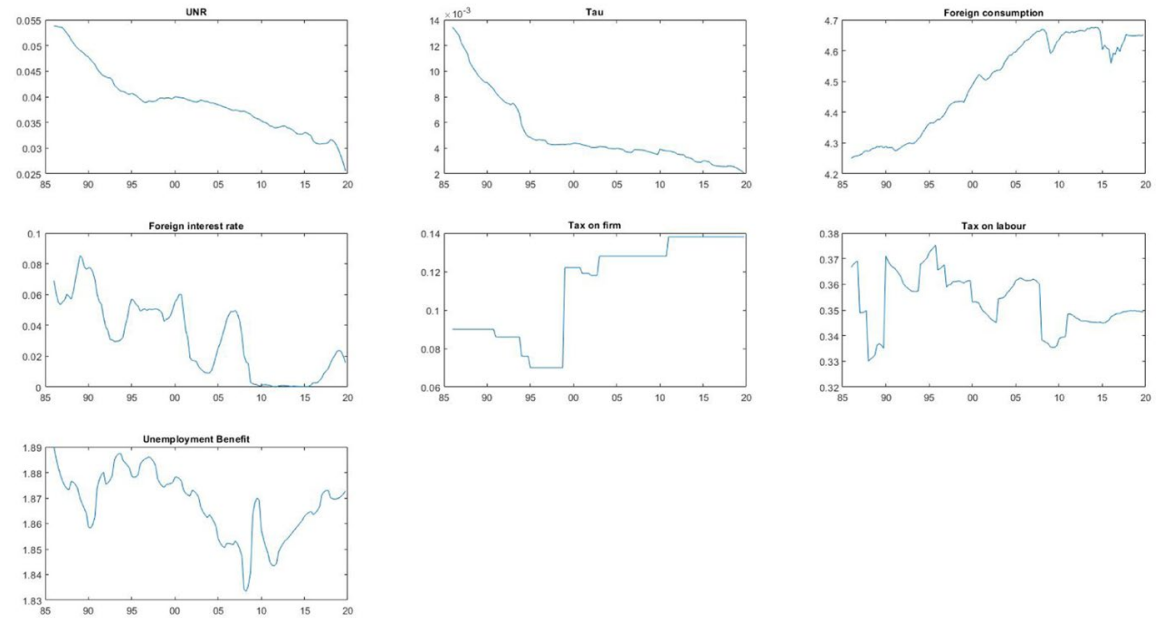

Fig. 12 Exogenous Variables

\section{Innovations}

See Figs. 13 and 14 

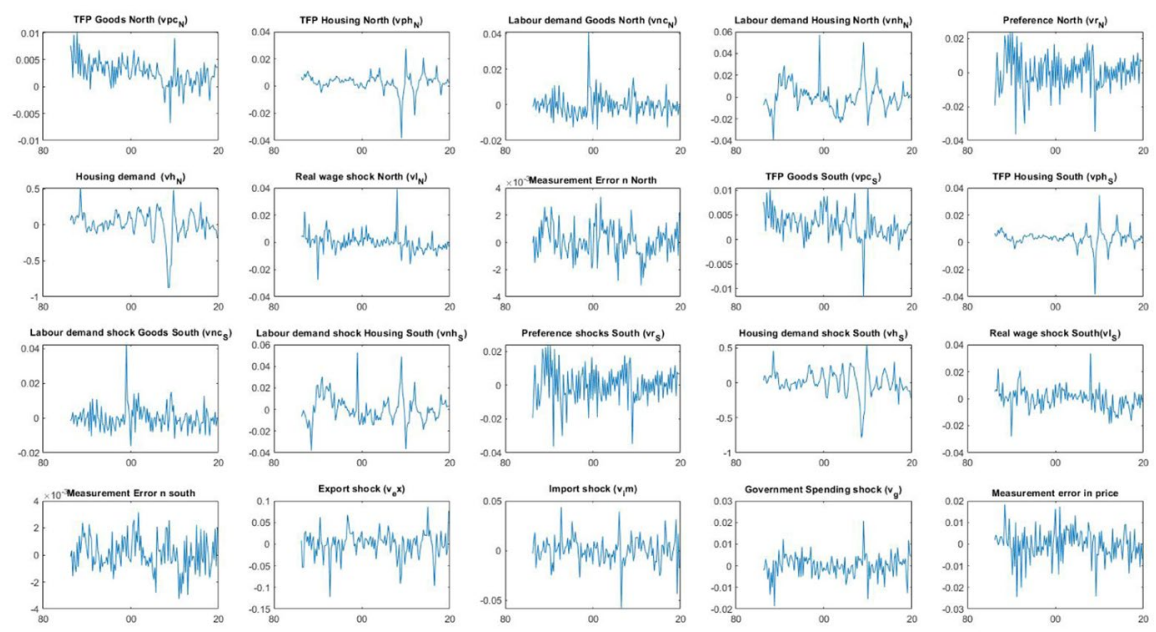

Fig. 13 Model Innovations
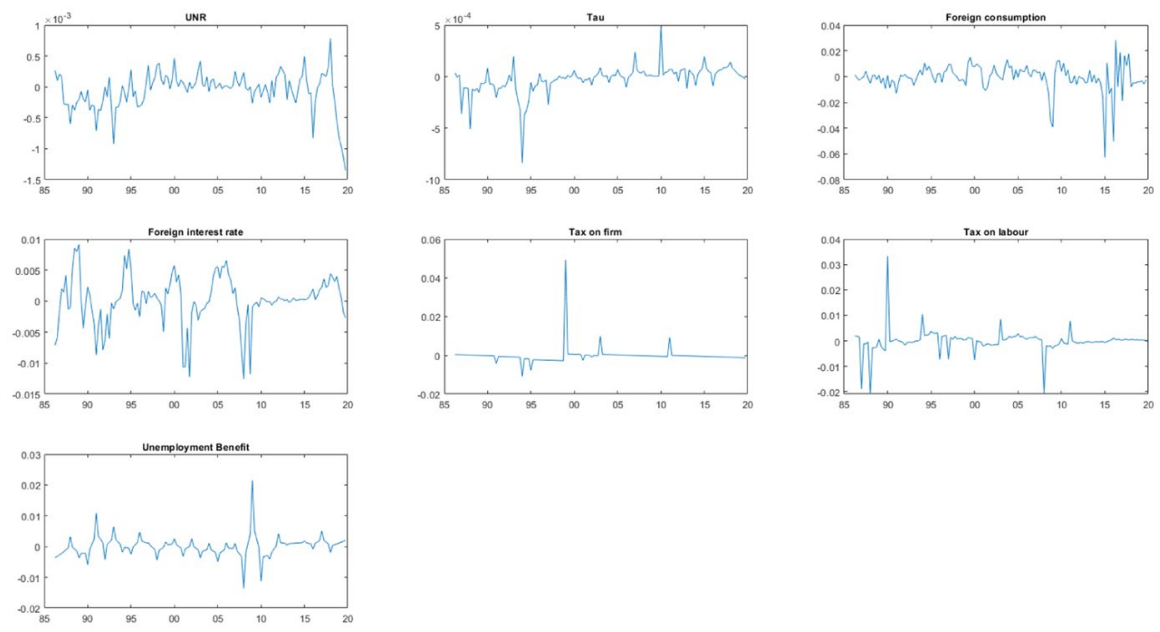

Fig. 14 Exogenous Innovations

\section{Appendix 4}

\section{Impulse Response Functions}

See Figs. 15, 16, 17, 18, and 19 

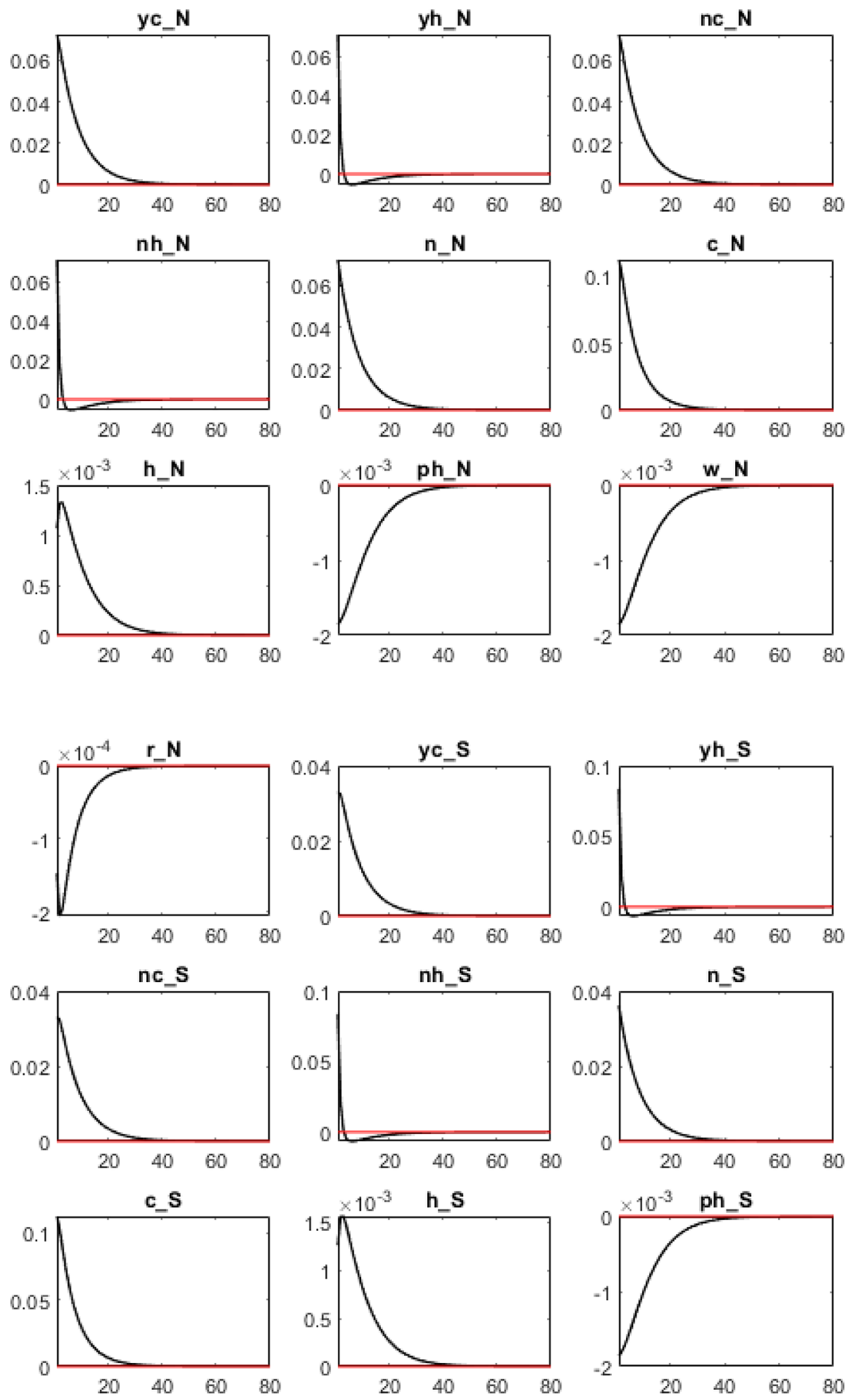

Fig. 15 Tax Cut on Labour Shock (Standard error: 0.1) 

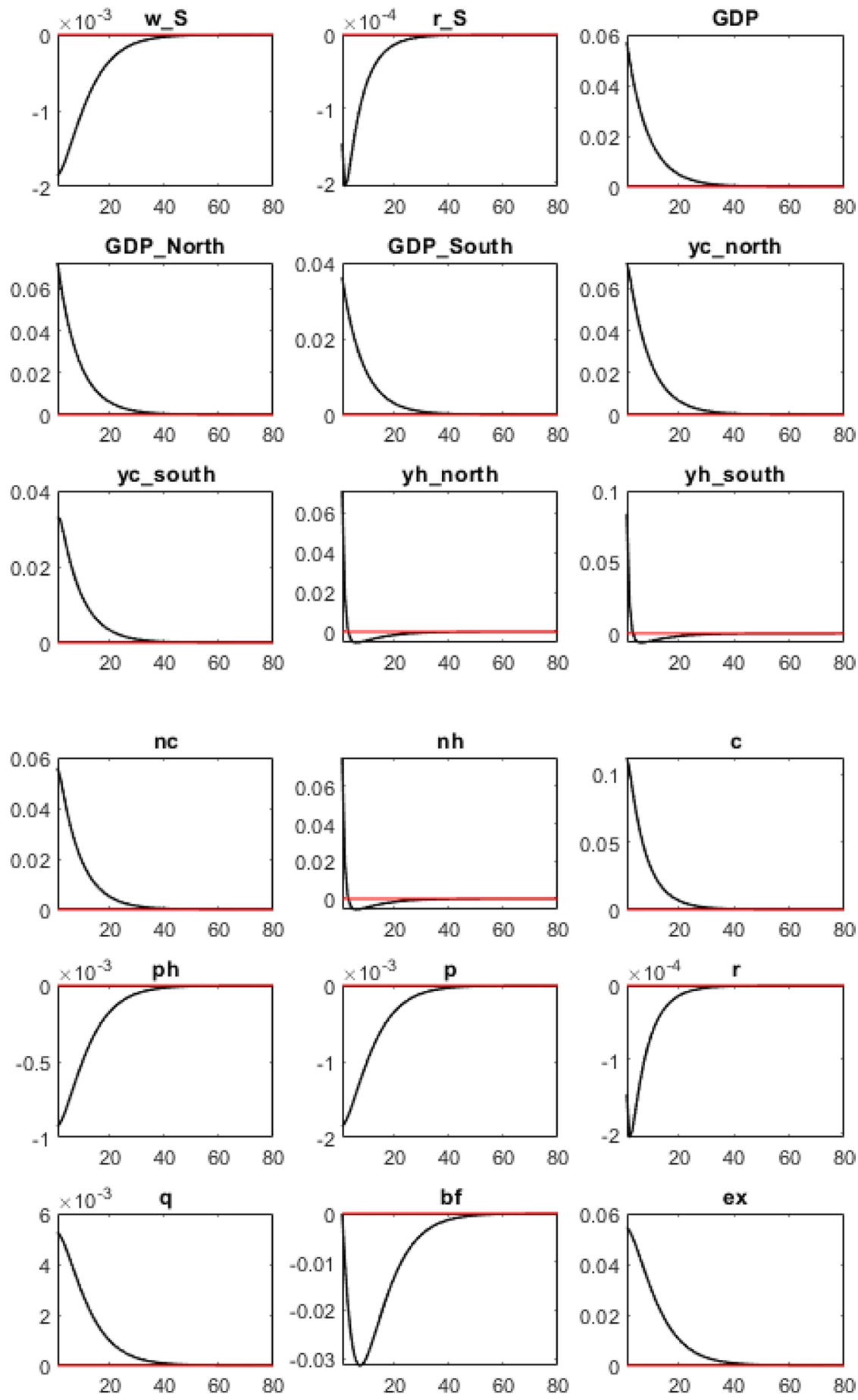

Fig. 15 (continued) 

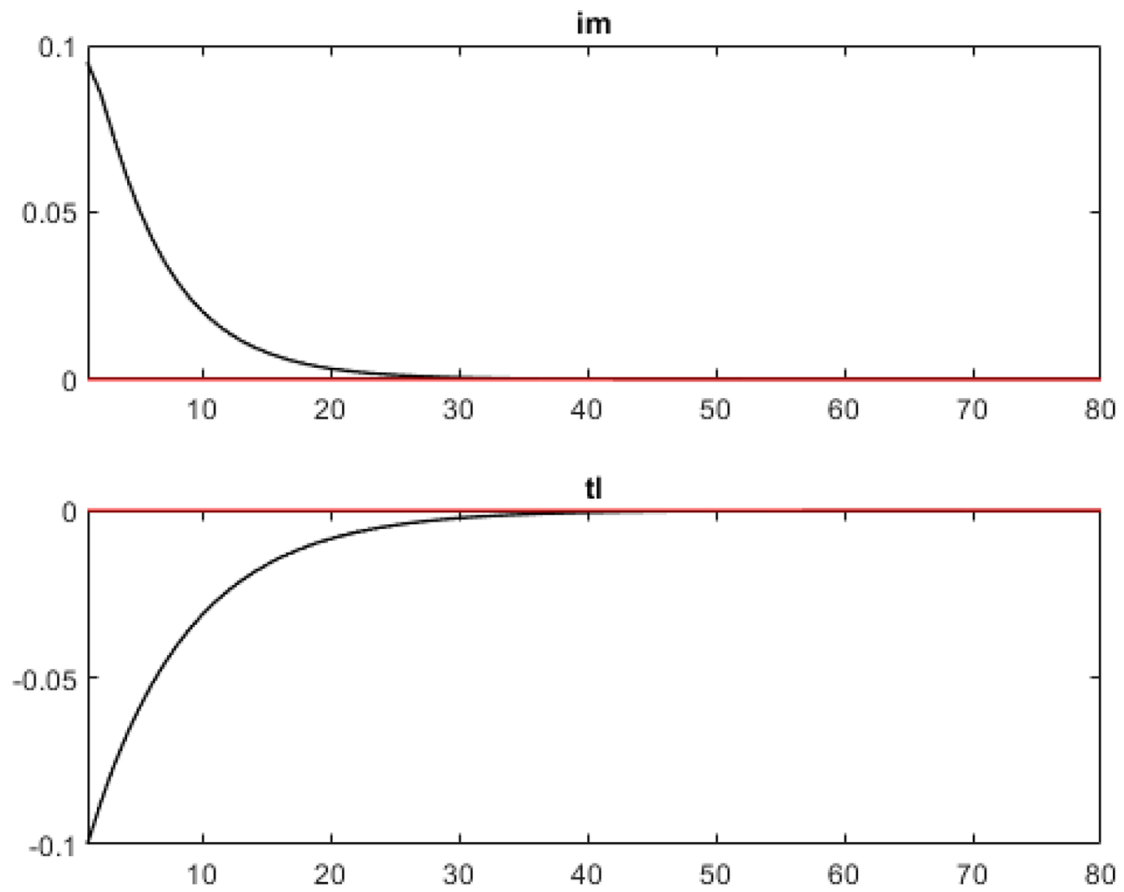

Fig. 15 (continued)
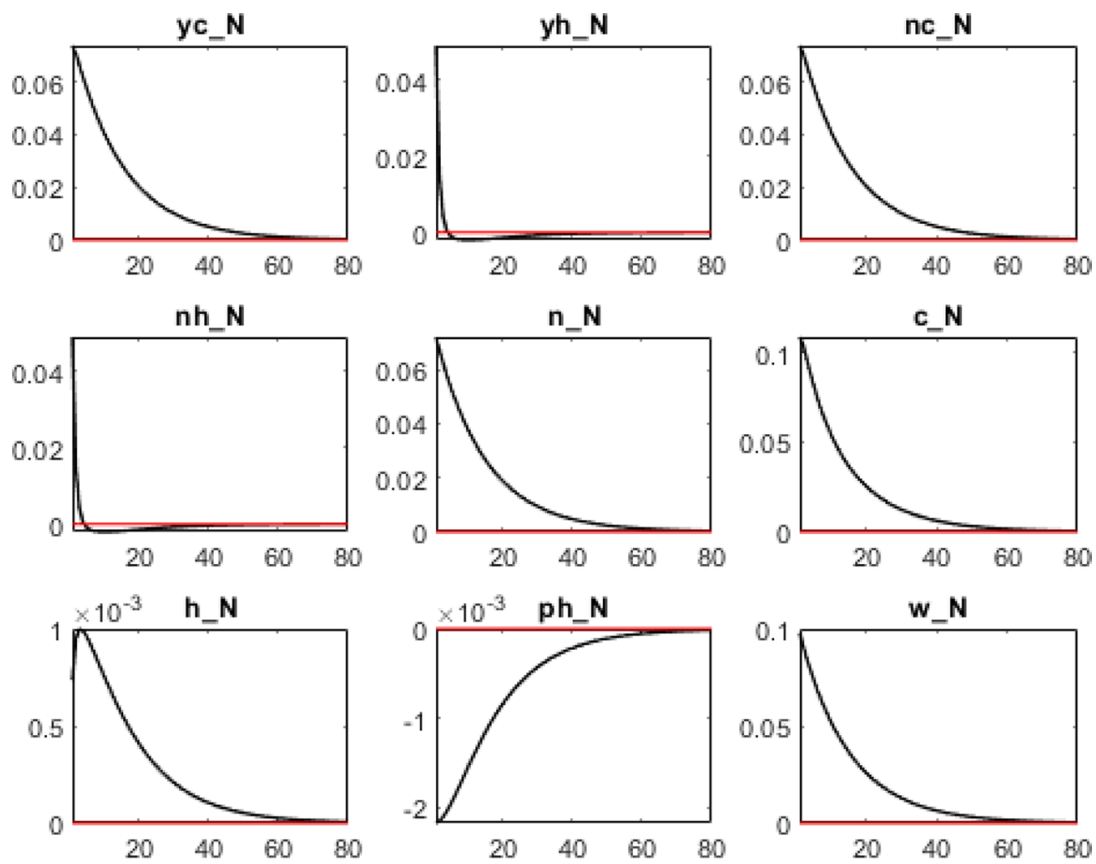

Fig. 16 Tax Cut on Firm Shock (Standard error: 0.1) 

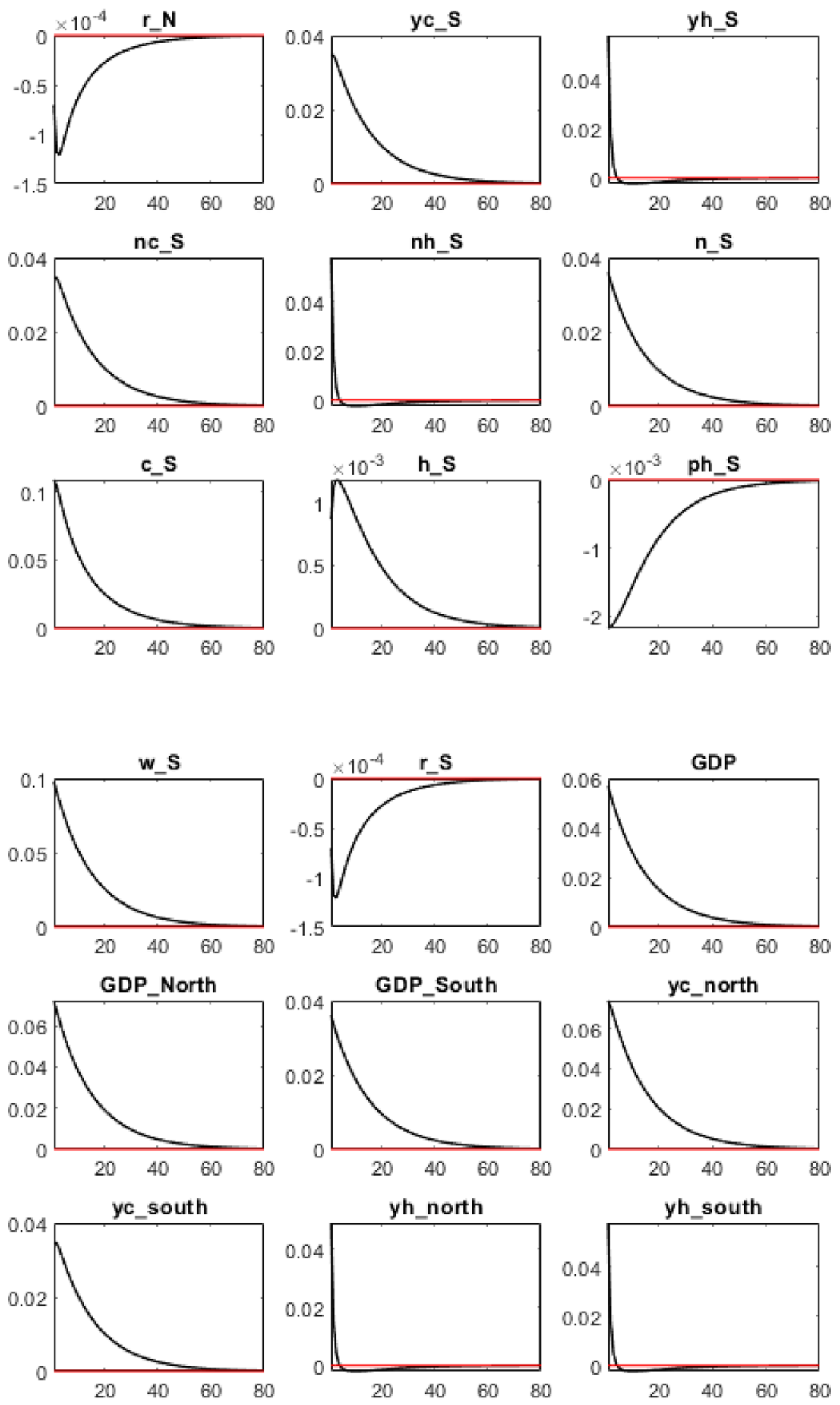

Fig. 16 (continued) 

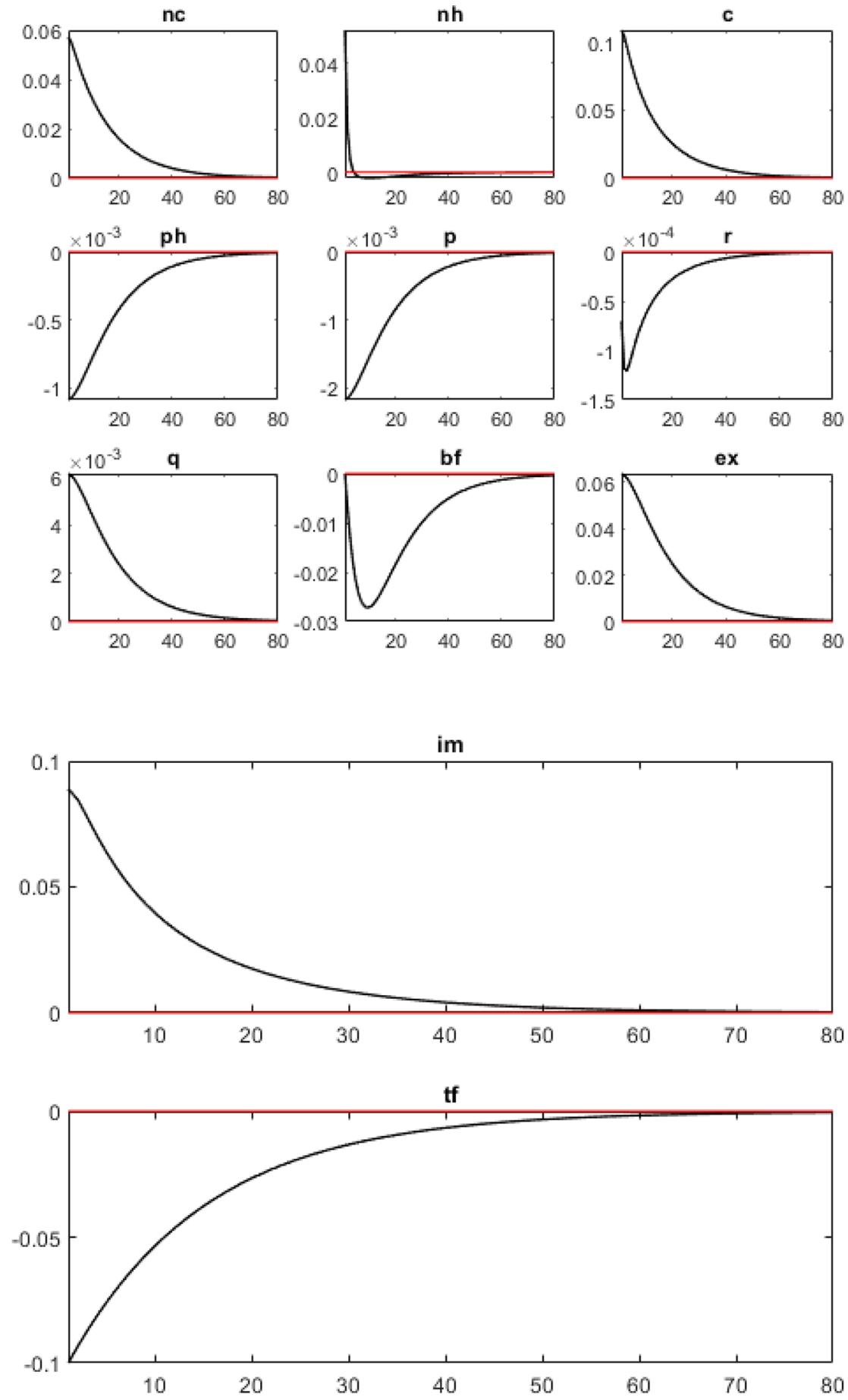

Fig. 16 (continued) 

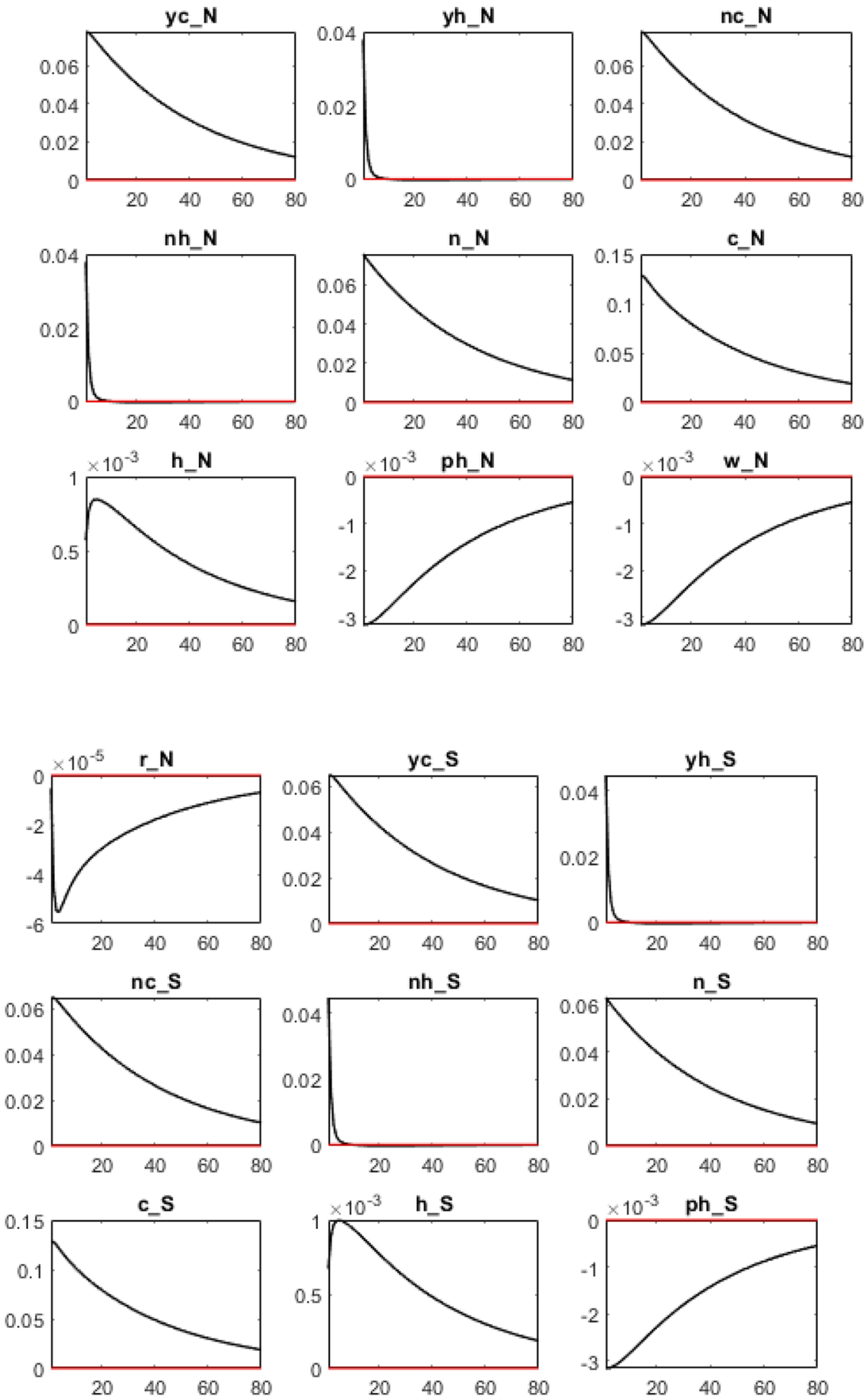

Fig. 17 Shock Reduction in UNR (Standard error: 0.1) 

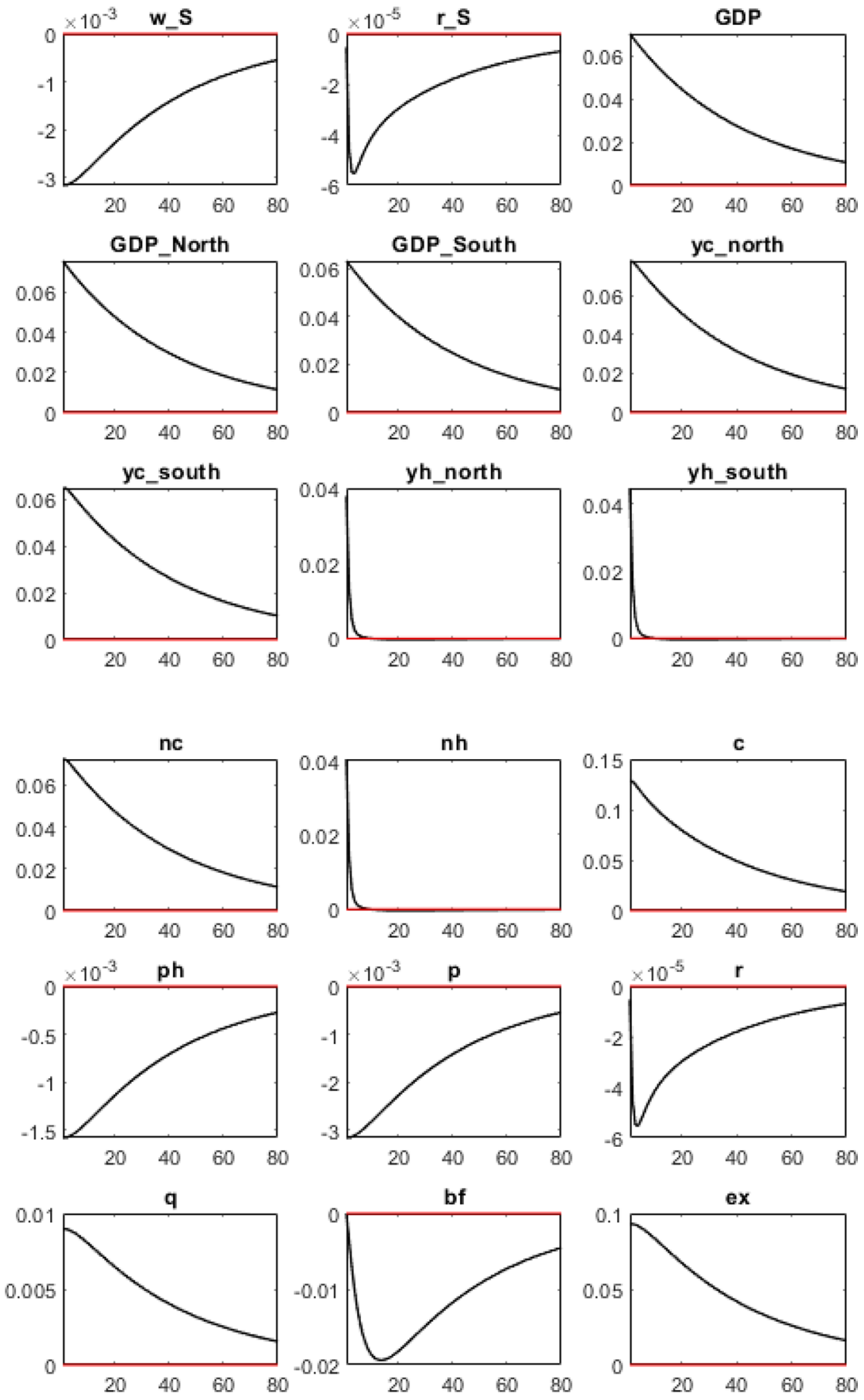

Fig. 17 (continued) 

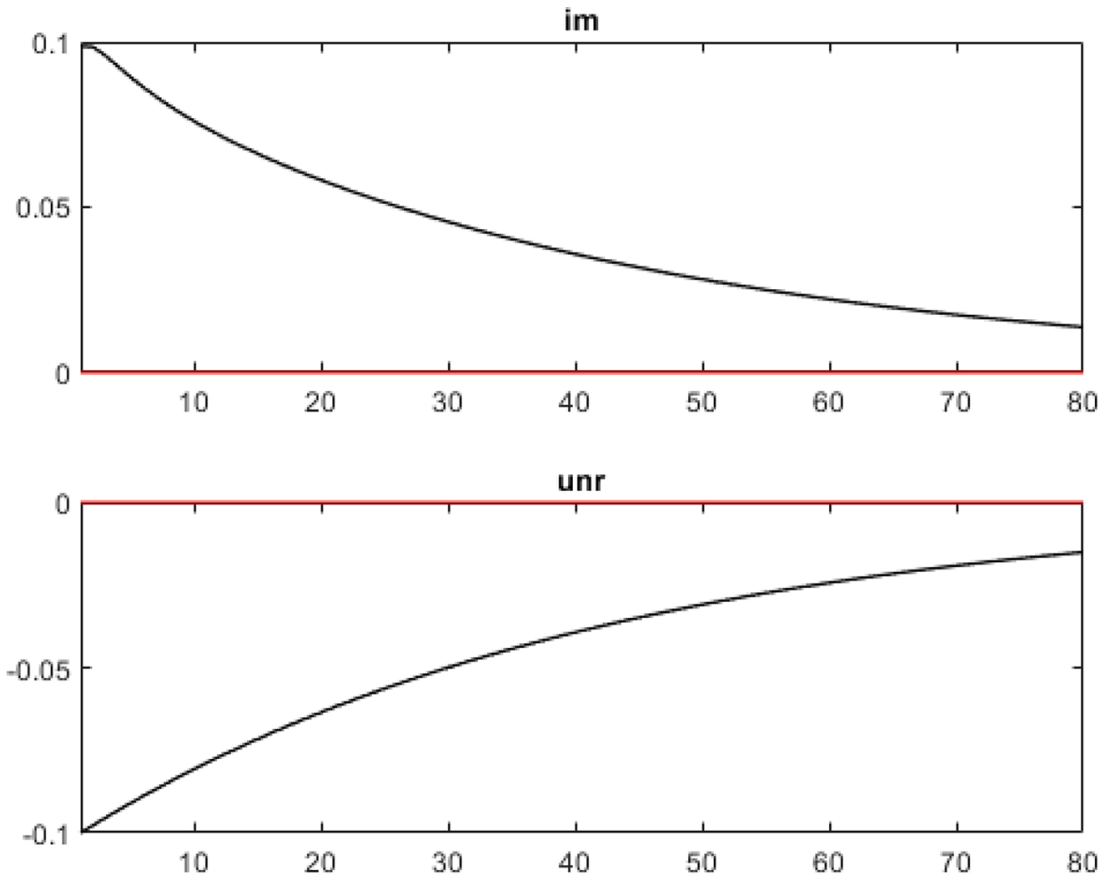

Fig. 17 (continued)
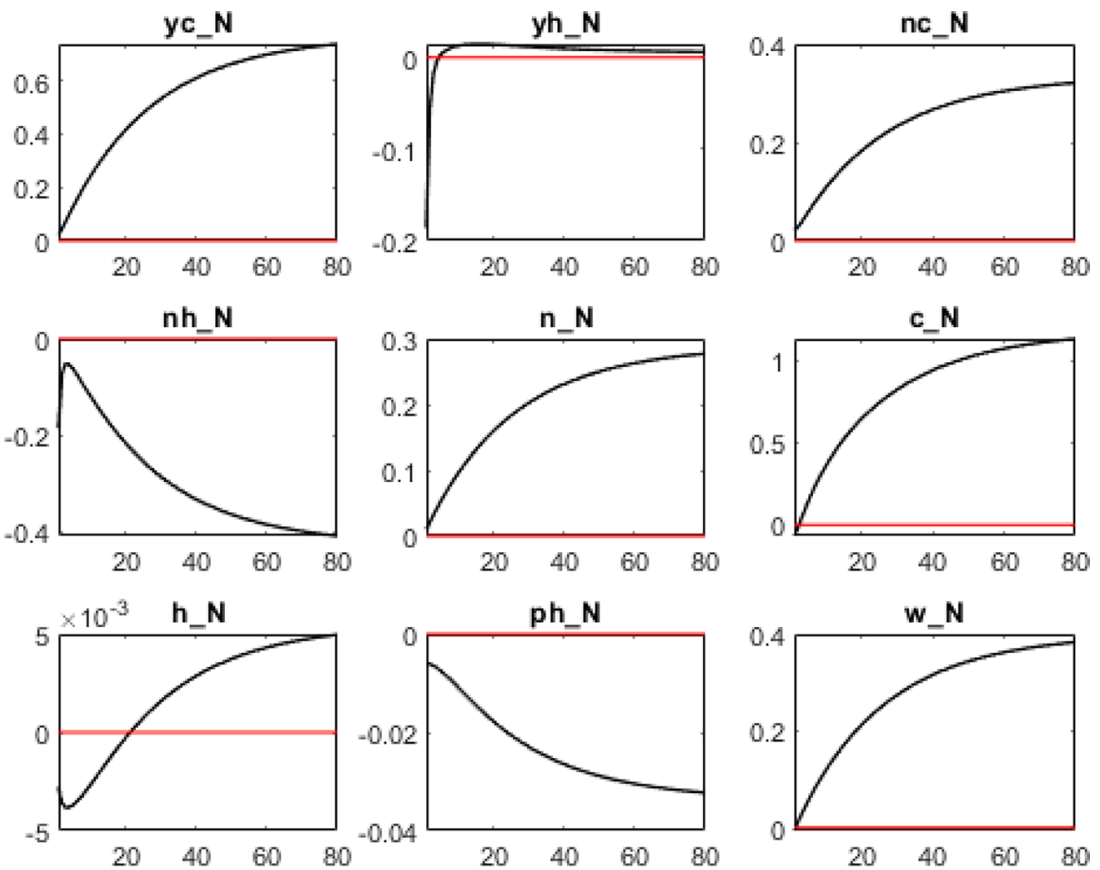

Fig. 18 Tax on Innovation Shock (Standard error: 0.1) 

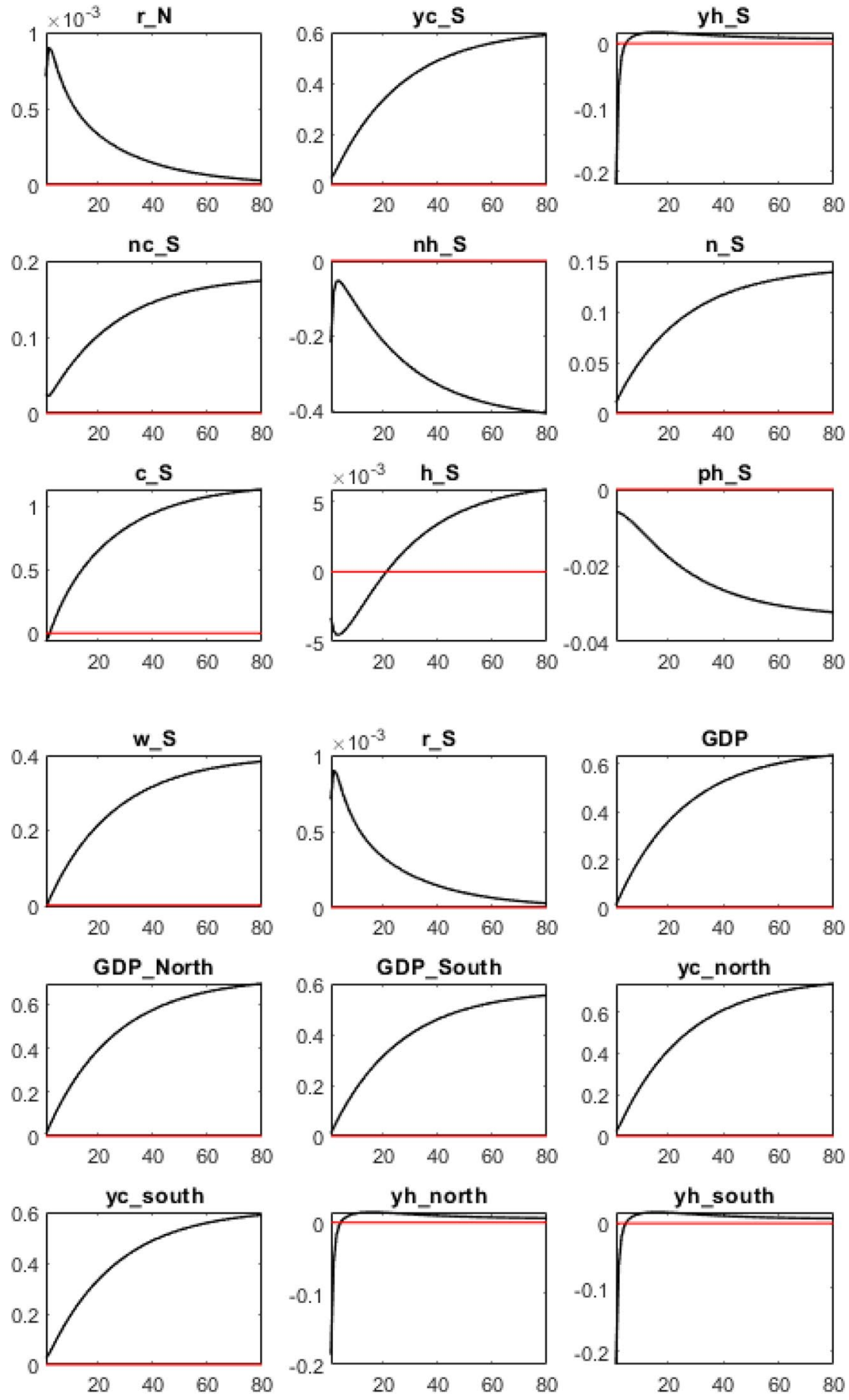

Fig. 18 (continued) 

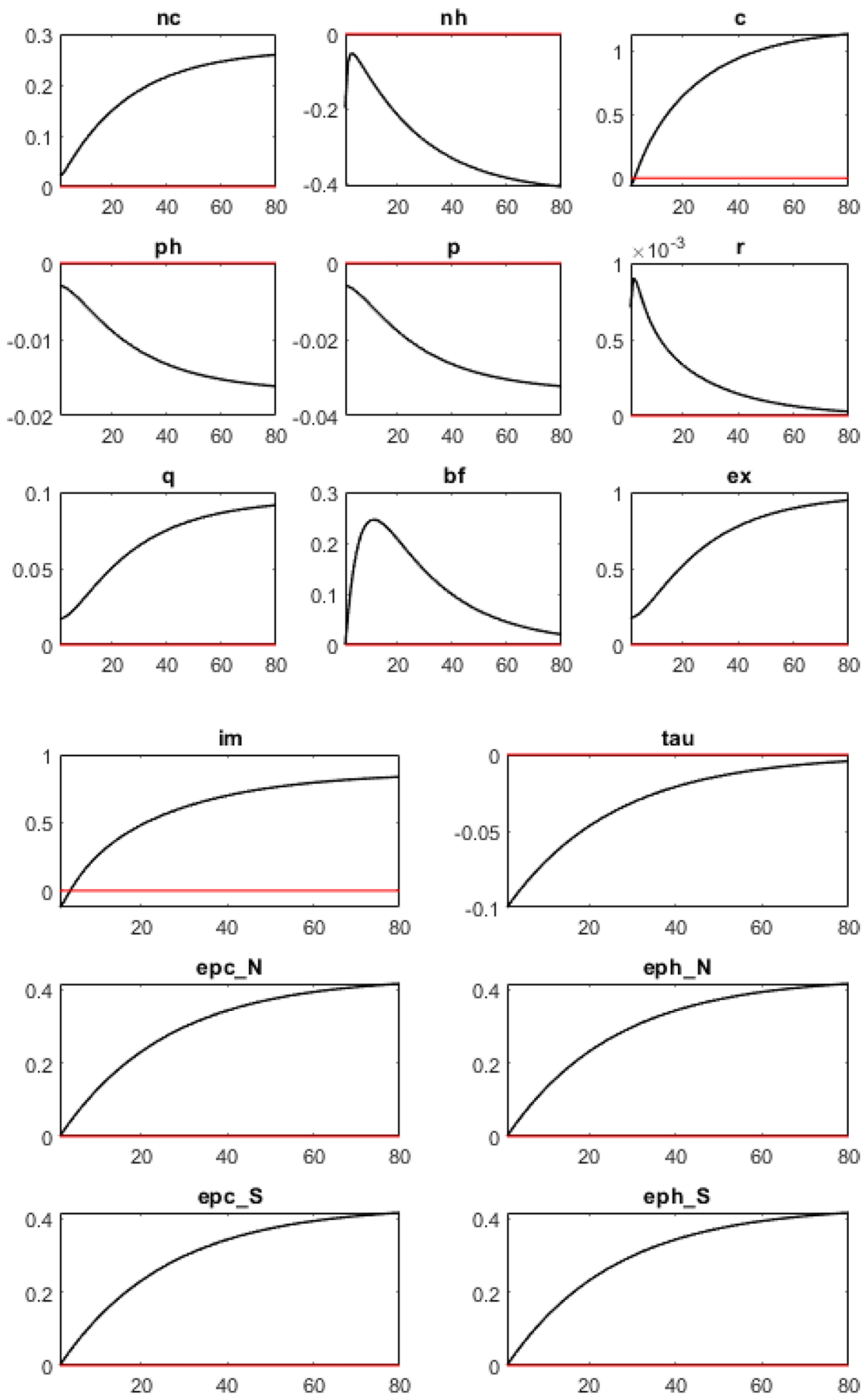

Fig. 18 (continued) 

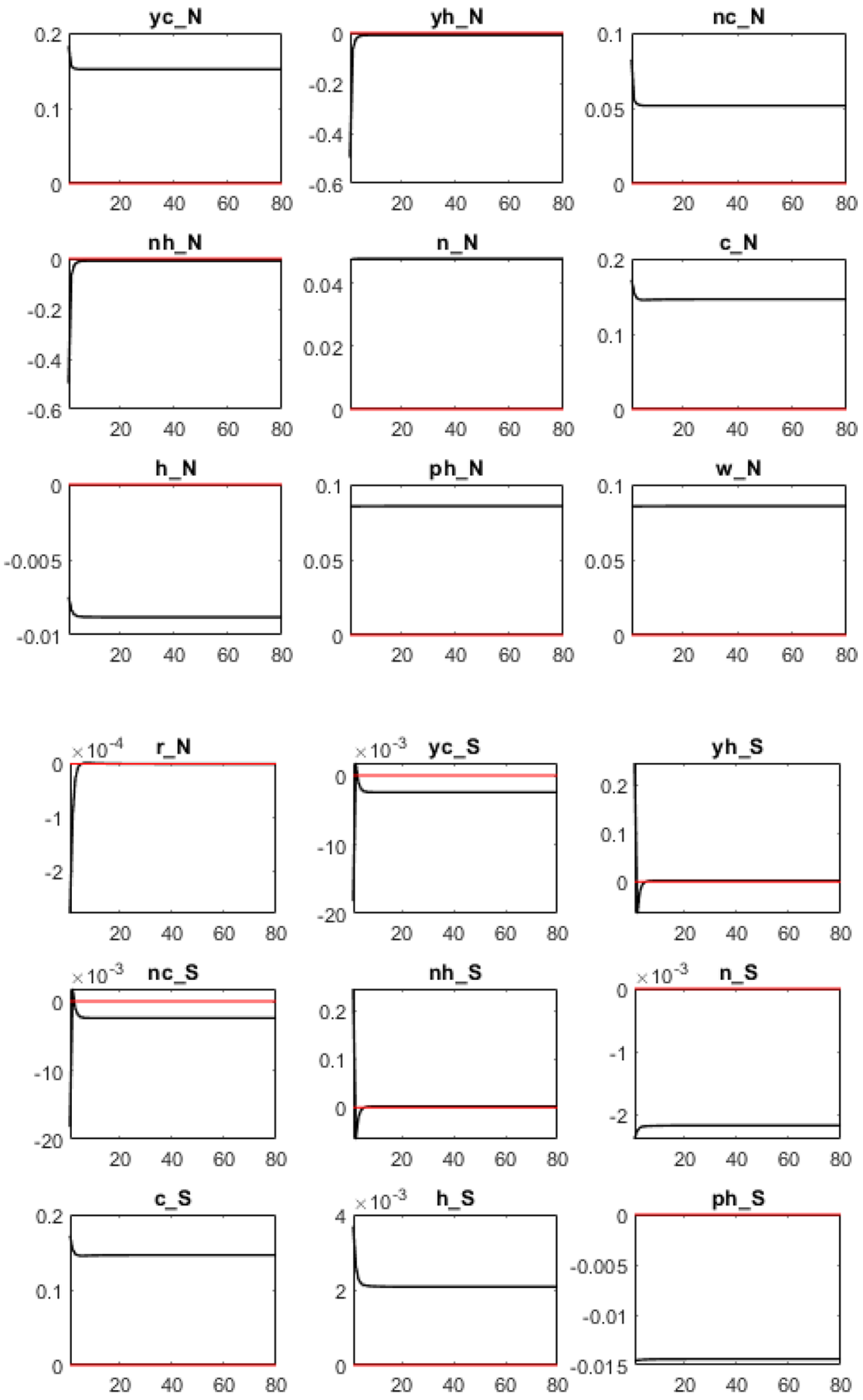

Fig. 19 Positive Productivity Shock in Goods Sector in North (Standard error: 0.1) 

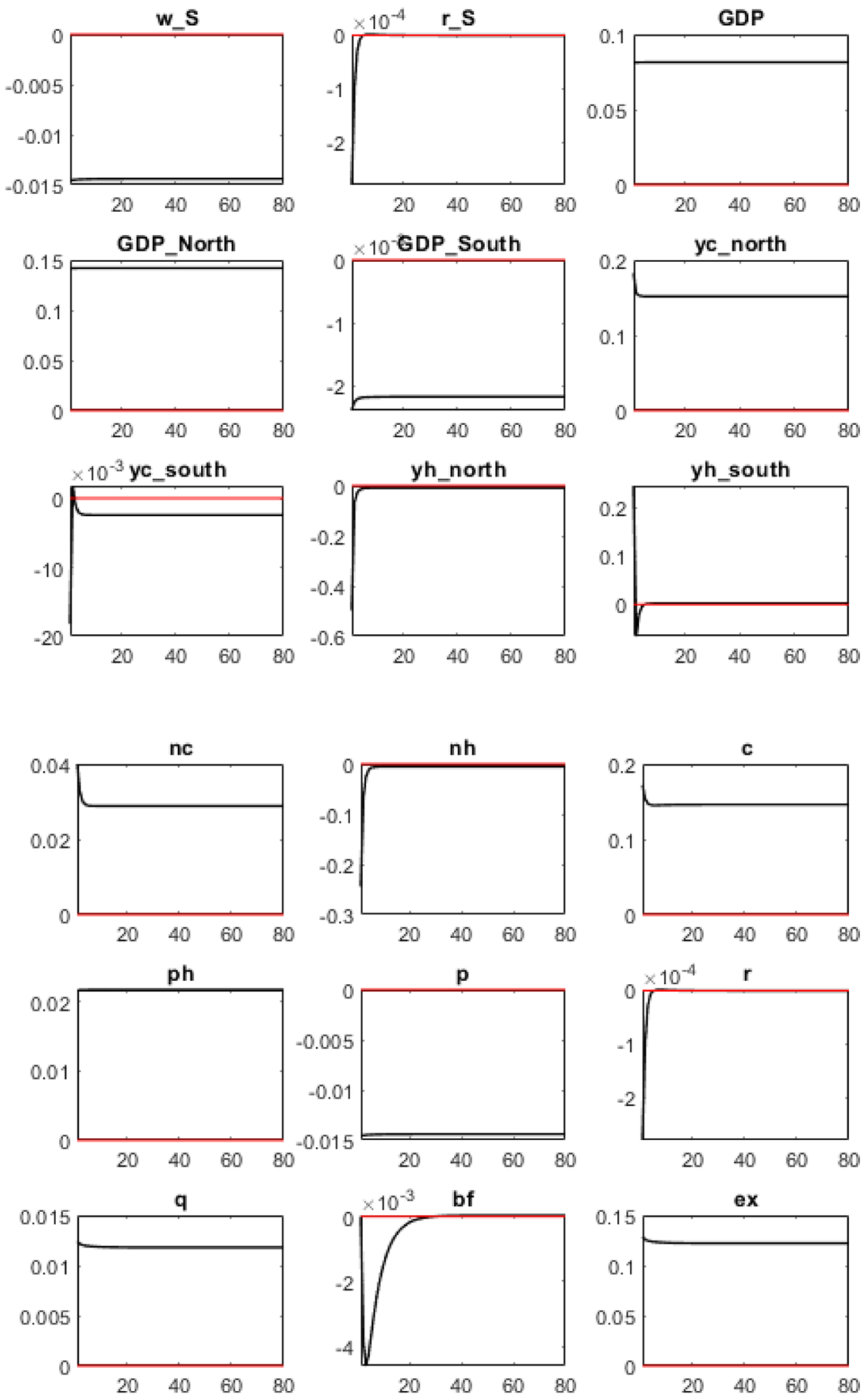

Fig. 19 (continued) 

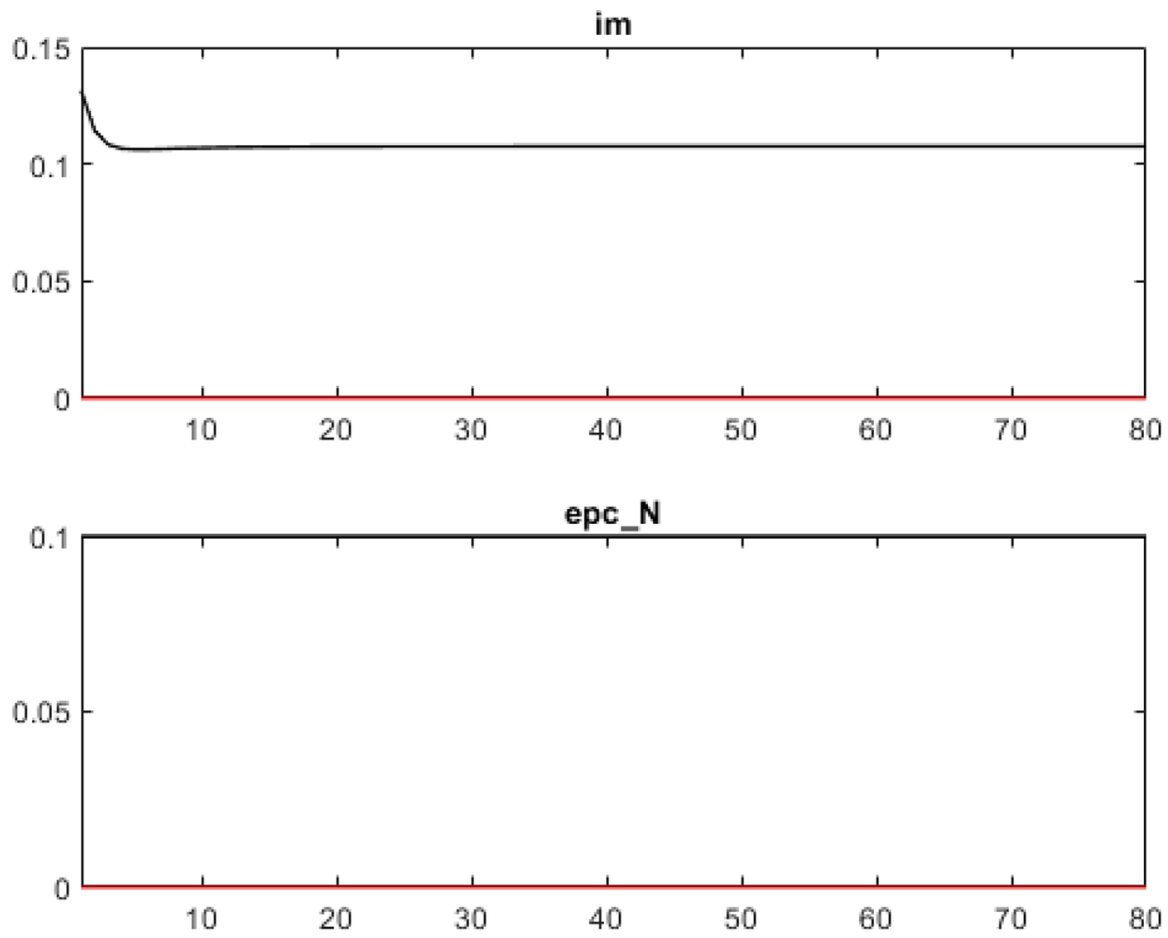

Fig. 19 (continued)

Funding Not applicable.

Data Availability All data generated or analysed during this study are included in this published article (and its supplementary information files).

Code Availibility Available on Acceptance

\section{Declarations}

Conflicts of Interest The authors declare that they have no conflict of interest.

Open Access This article is licensed under a Creative Commons Attribution 4.0 International License, which permits use, sharing, adaptation, distribution and reproduction in any medium or format, as long as you give appropriate credit to the original author(s) and the source, provide a link to the Creative Commons licence, and indicate if changes were made. The images or other third party material in this article are included in the article's Creative Commons licence, unless indicated otherwise in a credit line to the material. If material is not included in the article's Creative Commons licence and your intended use is not permitted by statutory regulation or exceeds the permitted use, you will need to obtain permission directly from the copyright holder. To view a copy of this licence, visit http://creativecommons.org/ licenses/by/4.0/. 


\section{References}

Akcigit U, Kerr WR (2018) Growth through heterogeneous innovations. J Polit Econ 126(4):1374-1443

Borts GH, Stein JL (1964) Economic growth in a free market. New York: Columbia University Press

Chari VV, Kehoe PJ, McGrattan ER (2002) Can sticky price models generate volatile and persistent real exchange rates? Rev Econ Stud 69(3):533-563

Coyle D, Sensier M (2019) The imperial treasury: Appraisal methodology and regional economic performance in the UK. In: Regional Studies

Dave C, DeJong DN (2007) Structural Macroeconometrics. Princeton University Press Princeton, New Jersey

Guvenen F, Smith AA (2014) Inferring labor income risk from economic choices: An indirect inference appproach. Econometrica 82(6):2085-2129

Henley A (2005) Job creation by the self-employed: The roles of entrepreneurial and financial capital. Small Bus Econ 25(2):175-196

Kollmann R, Pataracchia B, Raciborski R, Ratto M, Roeger W, Vogel L (2016) The post-crisis slump in the euro area and the us: Evidence from an estimated three-region dsge model. Eur Econ Rev $88: 21-41$

Krugman P, Venables AJ (1995) Globalization and the inequality of nations. Q J Econ 110(4):857-880

Kydland FE, Prescott EC (1982) Time to build and aggregate fluctuations. Econometrica: J Econ Soc 1345-1370

Le VPM, Meenagh D, Minford P, Wickens M (2010) Two orthogonal continents? Testing a two-country DSGE model of the US and the EU using indirect inference. Open Econ Rev 21(1):23-44

Le VPM, Meenagh D, Minford P, Wickens M (2011) How much nominal rigidity is there in the US economy? Testing a new Keynesian DSGE model using indirect inference. J Econ Dyn Control 35(12):2078-2104

Le VPM, Meenagh D, Minford P, Wickens M, Xu Y (2016) Testing macro models by indirect inference: a survey for users. Open Econ Rev 27(1):1-38

Lucas JR, Robert E (1990) Supply-side economics: An Analytical. Oxf Econ Pap, New Series 42(2):293-316

Marwaha S, Minford P, Matthews K, Sprague A (1984) The liverpool macroeconomic model of the united kingdom. Econ Model 1(1):24-62

Meenagh D, Minford P, Nowell E, Sofat P (2010) Can a real business cycle model without price and wage stickiness explain UK real exchange rate behaviour? J Int Money Financ 29(6):1131-1150

Meenagh D, Minford P, Wickens M, Xu Y (2019) Testing DSGE models by indirect inference: a survey of recent findings. Open Econ Rev 1-28

Menon C (2012) The bright side of MAUP: Defining new measures of industrial agglomeration. Pap Reg Sci 91(1):3-28

Minford L, Meenagh D (2019) Testing a model of UK growth: A role for R\&D subsidies. Econ Model 82:152-167

Minford P, Ashton P (1991) The poverty trap and the laffer curve-what can the GHS tell us? Oxf Econ Pap 43(2):245-279

Minford P, Peel D (2019) Advanced macroeconomics: a primer. Edward Elgar Publishing

Minford P, Xu Y (2018) Classical or gravity? Which trade model best matches the UK facts? Open Econ Rev 29(3):579-611

Philip L, Robert F, Katheryn R, Maurice O (2014) In search of the Armington elasticity. In: NBER Working Papers

Smith Jr AA (1993) Estimating nonlinear time-series models using simulated vector autoregressions. J Appl Economet 8(S1):S63-S84

Venables AJ (2020) Why some places are left behind: Urban adjustment to trade and policy shocks. Oxf Rev Econ Policy 36(3):604-620

Wickens M (2014) How useful are DSGE macroeconomic models for forecasting? Open Econ Rev 25(1):171-193

Publisher's Note Springer Nature remains neutral with regard to jurisdictional claims in published maps and institutional affiliations. 